\title{
Article \\ Gadolinium Protects Arabidopsis thaliana against Botrytis cinerea through the Activation of JA/ET-Induced Defense Responses
}

\author{
Juliana Santos Batista-Oliveira ${ }^{1,2}$, Damien Formey ${ }^{1}{ }^{\mathbb{D}}$, Martha Torres ${ }^{1}{ }^{1}$, Wendy Aragón ${ }^{1}$, Yordan \\ Jhovani Romero-Contreras ${ }^{1}$, Israel Maruri-López ${ }^{1}$, Alexandre Tromas ${ }^{1}$, Kátia Regina Freitas Schwan-Estrada ${ }^{2}$ \\ and Mario Serrano ${ }^{1, * \mathbb{D}}$
}

Citation: Batista-Oliveira, J.S.; Formey, D.; Torres, M.; Aragón, W.; Romero-Contreras, Y.J.;

Maruri-López, I.; Tromas, A.;

Schwan-Estrada, K.R.F.; Serrano, M. Gadolinium Protects Arabidopsis thaliana against Botrytis cinerea through the Activation of JA/ET-Induced Defense Responses. Int. J. Mol. Sci. 2021, 22, 4938 https://doi.org/10.3390/ijms22094938

Academic Editor: Cecilia Brunetti

Received: 6 April 2021

Accepted: 21 April 2021

Published: 6 May 2021

Publisher's Note: MDPI stays neutral with regard to jurisdictional claims in published maps and institutional affiliations.

Copyright: (c) 2021 by the authors. Licensee MDPI, Basel, Switzerland. This article is an open access article distributed under the terms and conditions of the Creative Commons Attribution (CC BY) license (https:/ / creativecommons.org/licenses/by/ $4.0 /)$
1 Centro de Ciencias Genómicas, Universidad Nacional Autónoma de México, Av. Universidad 2001, Cuernavaca, Morelos 62209, Mexico; julianaglomer@hotmail.com (J.S.B.-O.); formey@ccg.unam.mx (D.F.); mctorres@ccg.unam.mx (M.T.); waragon@ccg.unam.mx (W.A.); jhroco@ccg.unam.mx (Y.J.R.-C.); ismaruri@ccg.unam.mx (I.M.-L.); alexandre.tromas@gmail.com (A.T.)

2 Departamento de Agronomia, Universidade Estadual de Maringá, Maringá 87020, Brazil; krfsestrada@uem.br * Correspondence: serrano@ccg.unam.mx

\begin{abstract}
Plant food production is severely affected by fungi; to cope with this problem, farmers use synthetic fungicides. However, the need to reduce fungicide application has led to a search for alternatives, such as biostimulants. Rare-earth elements (REEs) are widely used as biostimulants, but their mode of action and their potential as an alternative to synthetic fungicides have not been fully studied. Here, the biostimulant effect of gadolinium (Gd) is explored using the plant-pathosystem Arabidopsis thaliana-Botrytis cinerea. We determine that Gd induces local, systemic, and long-lasting plant defense responses to B. cinerea, without affecting fungal development. The physiological changes induced by Gd have been related to its structural resemblance to calcium. However, our results show that the calcium-induced defense response is not sufficient to protect plants against B. cinerea, compared to $\mathrm{Gd}$. Furthermore, a genome-wide transcriptomic analysis shows that $\mathrm{Gd}$ induces plant defenses and modifies early and late defense responses. However, the resistance to B. cinerea is dependent on JA/ET-induced responses. These data support the conclusion that Gd can be used as a biocontrol agent for $B$. cinerea. These results are a valuable tool to uncover the molecular mechanisms induced by REEs.
\end{abstract}

Keywords: Arabidopsis thaliana; biostimulant; Botrytis cinerea; defense responses; gadolinium; rare-earth elements

\section{Introduction}

Two major factors determine the quantity and quality of plant-derived food: growth and development in the field and postharvest handling and storage conditions. Once a product is harvested, damage induced by microorganisms can cause $25 \%$ to $50 \%$ of the food to be lost [1]. Fungi of the genera Alternaria, Aspergillus, Botrytis, Fusarium, Geotrichum, Gloeosporium, Penicillium, Mucor, and Rhizopus are responsible for most of these losses [2,3]. In particular, the ubiquitous necrotrophic fungus Botrytis cinerea (Pers) has been shown to infect more than 200 plant species and to be responsible for "botrytis bunch rot" or "grey mold" symptoms. Due to these characteristics, B. cinerea has been classified as the second most important phytopathogen in existence [3]. To reduce the damage caused by B. cinerea and other fungi, farmers use different chemicals, including fungicides and biostimulants. The latter have been proposed as a new eco-friendly alternative to synthetic fungicides and are defined as naturally occurring molecules, elicitors, or microorganisms that enhance plant development, abiotic and biotic stress resistance, and/or crop quality traits $[4,5]$.

Biostimulants that activate plant defense responses include polypeptides; glycoproteins; lipids; proteins; glycolipids; oligosaccharides; and microbe-, herbivore-, and damage- 
associated molecular patterns [4-6]. Defense responses primed by biostimulants include the activation of the plant innate immunity and the late defense responses. As part of the immune response, the accumulation of reactive oxygen species (ROS), calcium $\left(\mathrm{Ca}^{2+}\right)$ influx, protein phosphorylation, mitogen-activated protein kinase (MAPK) signaling, and transcriptional induction of the early defense response genes take place [7-9]. After the initial response, the secondary defense responses are activated, including the production of histological barriers such as callose or lignin and the induction of salicylic acid-(SA), jasmonic acid-(JA), and ethylene-(ET) dependent signaling pathways [10]. These pathways finally lead to the induction of systemic acquired resistance (SAR) in non-infected distal organs of the plant $[6,11,12]$. The combined effect of these defense responses can efficiently stop disease induced by non-adapted pathogens, including fungi.

Rare-earth elements (REEs) are trace metals from the lanthanide group. While REEs are not known to be nutritionally essential to plants, they have been used as biostimulants in agriculture, particularly in China, to improve plant growth and development [13-16]. Depending on their concentration, REEs can have positive and negative effects on plant growth, development, and production (see reviews $[17,18]$ ). For instance, the application of a low concentration of neodymium $(1,3$ or $5 \mathrm{mg} / \mathrm{L})$ improved the germination rates of Cassia obtusifolia seeds, while higher concentrations inhibited them [19]. On the other hand, the application of $6 \mathrm{mg} / \mathrm{L}$ of neodymium increased the germination rates of Astragalus membranaceu seeds up to $42 \%$ [18], suggesting that the beneficial effects of REEs depend not only on the concentration but also on the plant species. Nevertheless, the beneficial effects of REEs have been related to their structural chemical resemblance to the secondary messenger, calcium [20]. Many REEs can displace the divalent $\mathrm{Ca}$ cation due to their trivalent charges and thus higher charge density, modifying an increased number of Camediated biological processes [21]. In particular, calcium channels have been reported to be specifically blocked by the so-called "super calcium molecule" gadolinium, modifying multiple plant responses to abiotic and biotic stimuli [22,23]. Nevertheless, the effect of REEs on plant biology still remains mostly unknown [17]. For this reason, it is still not clear if the biological effects of REEs are only due to their structural chemical resemblance to $\mathrm{Ca}$ or to as-yet unknown mechanisms.

Nowadays, food production is based on the application of fertilizers-for instance, $18.8 \times 10^{10} \mathrm{Kg}$ of phosphate-based fertilizers are applied every year worldwide [24] REEs are found as minor components of the raw material of phosphate-based fertilizers (monazites) [25,26]. For this reason, REEs are constantly applied to plants as biostimulants and/or as part of fertilizers, although basic information about them, such as their molecular mechanisms and the transcriptional changes induced by their application, are mostly unknown. On the other hand, their possible use as an alternative to synthetic fungicides has not been fully explored either. Only a handful of reports have studied the effect of REEs during plant-microbe interactions, some with contradictory outcomes. Some of these studies have indicated that the application of REEs induces defense responses against brown blast disease in rubber trees and fusarium wilt in tomato $[27,28]$, while another report showed their inhibition of plant defense mechanisms [29]. Nevertheless, in order to become an alternative to synthetic fungicides, it is first necessary to properly characterize the molecular changes induced by REEs and then optimize their application and activity in the field.

In this report, we showed that the REE gadolinium $(\mathrm{Gd})$ is a biostimulant that improves the growth and development of $A$. thaliana roots. Additionally, we determined that $\mathrm{Gd}$ protects plants against the necrotrophic fungus $B$. cinerea, without affecting the development of the fungus itself. Gd has a dose-dependent and long-lasting effect, triggering local and systemic defense responses against $B$. cinerea. To our knowledge, this is the first report of change in the plant transcriptome induced by Gd during the interaction with $B$. cinerea using genome-wide analysis (RNA-seq). This information will be a valuable tool to uncover the molecular mechanisms induced by REEs and will help in future efforts to improve and fully exploit their use in agriculture. 


\section{Results}

\subsection{Gadolinium Improves Root Development of A. thaliana}

Our previous results indicated that the application of $0.2 \mathrm{~g} / \mathrm{L}$ of gadolinium (III) nitrate hexahydrate $\left(\mathrm{Gd}\left(\mathrm{NO}_{3}\right)_{3} \cdot 6 \mathrm{H}_{2} \mathrm{O}\right)$ has a positive effect on the development of Glycine max compared to plants treated with $0.2 \mathrm{~g} / \mathrm{L}$ of calcium nitrate $\left(\mathrm{Ca}\left(\mathrm{NO}_{3}\right)_{2}\right)$, henceforth identified as $\mathrm{Gd}$ and $\mathrm{Ca}$ [30]. Based on this observation and in order to better understand the molecular mechanisms induced by the exogenous application of gadolinium, we analyzed its effect on the model plant $A$. thaliana. A. thaliana seeds were germinated in the presence of distilled sterile water (as mock), $0.2 \mathrm{~g} / \mathrm{L} \mathrm{Ca}$, or $0.2 \mathrm{~g} / \mathrm{L} \mathrm{Gd}$. Ca was also used as a control because of its structural resemblance to $\mathrm{Gd}$. Ten days after germination, a significant increase in root length was observed in Gd-treated plants compared to mock- and Catreated samples (Figure 1A). Afterwards, the same seedlings were transplanted to soil and the number of leaves was counted 30 days later. Once more, we observed a slight increase in the number of leaves in Gd-induced samples compared to the mock- and Catreated samples. However, these differences were not statistically significant (Figure S1). Additionally, no changes in germination rate or fresh or dry weight were observed between the mock-, Ca-, and Gd-treated samples (Figure S1). Taken together, these results suggest that $\mathrm{Ca}$ did not affect $A$. thaliana growth and that exogenous Gd application improved the root growth of $A$. thaliana.
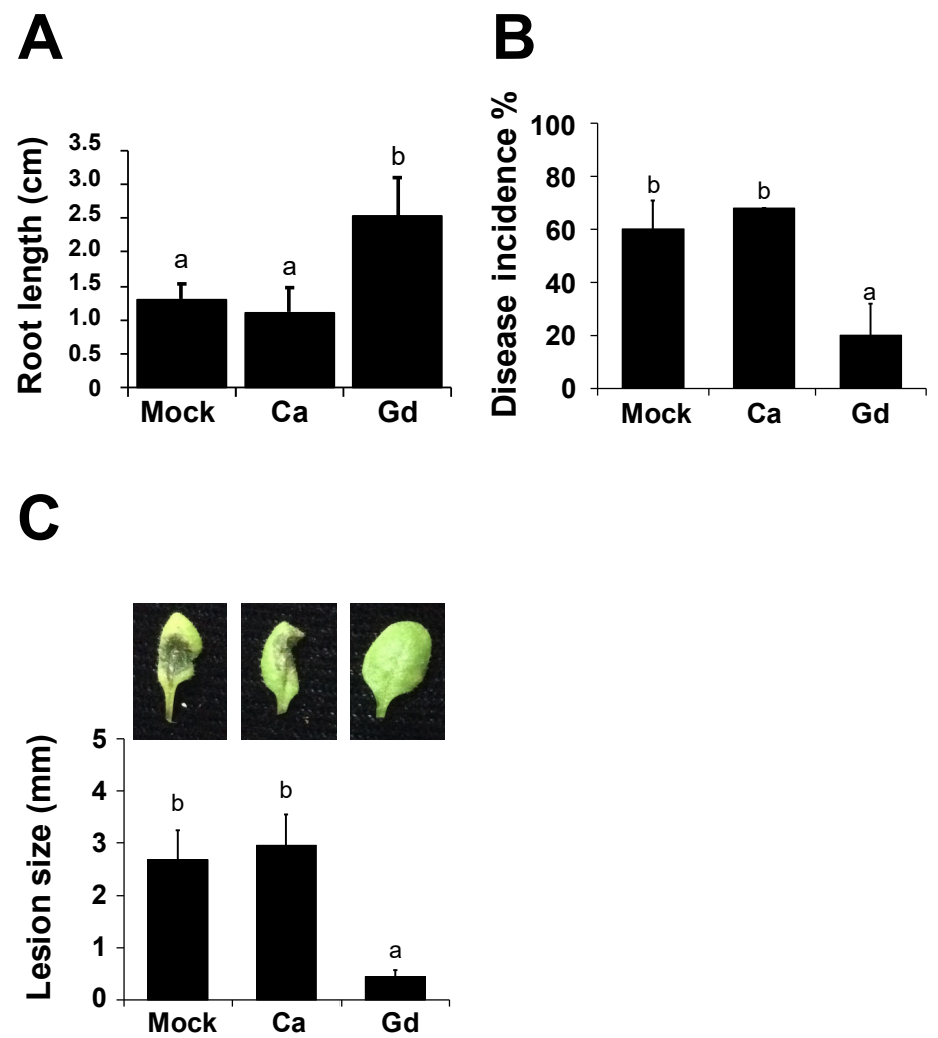

Figure 1. Gd improved the root development of $A$. thaliana and induced protection against $B$. cinerea. A. thaliana seeds were incubated for $1 \mathrm{~h}$ with distilled sterile water (mock), $0.2 \mathrm{~g} / \mathrm{L} \mathrm{Ca}$, or Gd and germinated under in vitro conditions. Ten days post germination, the primary root length was measured (A). Four-weeks-old $A$. thaliana plants were sprayed until saturation with distilled sterile water (mock), $0.2 \mathrm{~g} / \mathrm{L} \mathrm{Ca}$, or Gd (24 hpt). After this, $3 \mu \mathrm{L}$ droplets containing a B. cinerea spore suspension $\left(5 \times 10^{4}\right.$ spores $\left.\mathrm{mL}^{-1}\right)$ were applied and the $72 \mathrm{hpi}$ disease incidence $(\mathbf{B})$ and lesion size (C) were evaluated. A representative picture is included above each histogram as a visual illustration. Bars represent mean values $( \pm \mathrm{SD})$ of three independent experiments $(n=30$ for each experiment). Different letters above each bar represent statistically significant differences according to the Scott-Knott test $(p<0.05)$. 


\subsection{Gadolinium Protects Arabidopsis thaliana Plants against the Necrotrophic Pathogen B. cinerea}

Our next step was to determine if $\mathrm{Gd}$ has an effect in the well-characterized plantpathosystem $A$. thaliana-B. cinerea. Four-week-old $A$. thaliana plants were pre-treated for $24 \mathrm{~h} \mathrm{(hpt)} \mathrm{by} \mathrm{spraying} \mathrm{with} 0.2 \mathrm{~g} / \mathrm{L} \mathrm{Gd}$ or $\mathrm{Ca}$ and distilled sterile water (as mock) and afterwards infected with $B$. cinerea spores. First, we measured the percentage of plants showing disease symptoms $72 \mathrm{~h}$ post infection (hpi), expressed as disease incidence (Figure 1B). No statistical differences were observed between the mock- and Ca-treated plants, suggesting that $\mathrm{Ca}$ did not affect the $A$. thaliana-B. cinerea interaction. However, we observed a 50\% reduction in incidence in Gd-treated plants compared to Ca-treated control samples (Figure 1B). Additionally, when we characterized the disease severity by measuring the lesion size at $72 \mathrm{hpi}$, plants treated with Gd showed a strong reduction in the infection (almost to 80\%) compared to the control Ca-treated samples (Figure 1C). Taken together, these results indicate that the exogenous application of $\mathrm{Gd}$ causes a strong reduction in disease incidence and infection severity from the necrotrophic pathogen $B$. cinerea. Additionally, since we determined that $\mathrm{Ca}$ did not affect the $A$. thaliana-B. cinerea interaction compared to $\mathrm{H}_{2} \mathrm{O}$-treated plants (Figure $1 \mathrm{~B}, \mathrm{C}$ ) and in order to eliminate the possible phenotypes induced by the structural resemblance between $\mathrm{Ca}$ and $\mathrm{Gd}$, in the rest of the experiments we decided to use only $\mathrm{Ca}$ as a mock control.

\subsection{Gd Does Not Affect the Development of B. cinerea}

REEs have been shown to inhibit the development of several microorganisms $[31,32]$. To determine if the protective effect observed in plants (Figure 1C) was triggered either by the direct effect of Gd localized on the leaf surface or by the induction of the plant defense responses, we characterized the development of the pathogen in the presence of Gd under in vitro and in planta conditions (Figure 2). Spore suspensions, at a final concentration of $5 \times 10^{4}$ spores per $\mathrm{ml}$, were grown on a Petri dish containing PDA media supplemented with water (mock); $0.2 \mathrm{~g} / \mathrm{L} \mathrm{Ca}$; or Gd at $0.2,0.4,0.8$, and $1.6 \mathrm{~g} / \mathrm{L}$ and incubated under optimal growth conditions for 10 days. We determined that $\mathrm{Gd}$ did not inhibit the growth of B. cinerea mycelium at any of the treatments (Figure 2A). Additionally, to determine if $\mathrm{Gd}$ has an effect on the development of $B$. cinerea, the number of spores was quantified. Once more, no statistical differences were observed at either of the two concentrations $(0.2$ and $1.6 \mathrm{~g} / \mathrm{L} \mathrm{Gd}$ ) nor at $0.2 \mathrm{~g} / \mathrm{L} \mathrm{Ca}$, compared to the mock-treated samples (Figure 2B). To further characterize these observations, the fungal growth in planta was followed by trypan blue staining. At $24 \mathrm{hpi}$, no differences in the hyphal development between mock-, Ca-, and Gd-treated leaves were observed. However, at $48 \mathrm{hpi}$ the hyphal growth of $B$. cinerea on Gd-induced leaves was inhibited (Figure 2C). This suggests that the gemination of the spores was not modified, and while the initial compatible interaction between $B$. cinerea and $A$. thaliana might not be affected by Gd application, the progression of the infection is inhibited. Taken together, these results suggest that Gd induces a protective effect, as previously observed in planta (Figure 1), which could be mediated by the modifications of the plant defense responses rather than a direct effect on fungal growth and development.

\subsection{Gd-Induced Protection against B. cinerea Is Dose-Dependent and Long-Lasting}

To determine the optimal concentration of Gd-induced resistance against $B$. cinerea, a dose-dependent experiment was performed. We inoculated 4-week-old A. thaliana plants pre-treated for $24 \mathrm{hpt}$ with $0.05,0.1,0.2,0.4$, and $0.8 \mathrm{~g} / \mathrm{L} \mathrm{Gd}$, as well as $0.8 \mathrm{~g} / \mathrm{L} \mathrm{Ca}$ as a control, with B. cinerea spores, and measured the lesion size at $72 \mathrm{hpi}$ (Figure 3A). No protection against the pathogen was observed on plants treated with the lowest concentration of $\mathrm{Gd}(0.05 \mathrm{~g} / \mathrm{L}$, Figure $3 \mathrm{~A})$. However, samples pre-treated with 0.1 to $0.8 \mathrm{~g} / \mathrm{L}$ of Gd showed a strong reduction in lesion size of approximately $70 \%$, compared to Ca-treated control plants (Figure 3A). It is noteworthy that plants pre-treated with $1.6 \mathrm{~g} / \mathrm{L}$ of Gd showed spontaneous lesions and, for this reason, were not included in the analysis. These results show that a reduction in lesion size through the exogenous application of $\mathrm{Gd}$ is 
dose-dependent, with a strong inhibition of disease already occurring at a concentration of $0.1 \mathrm{~g} / \mathrm{L}$ of Gd.
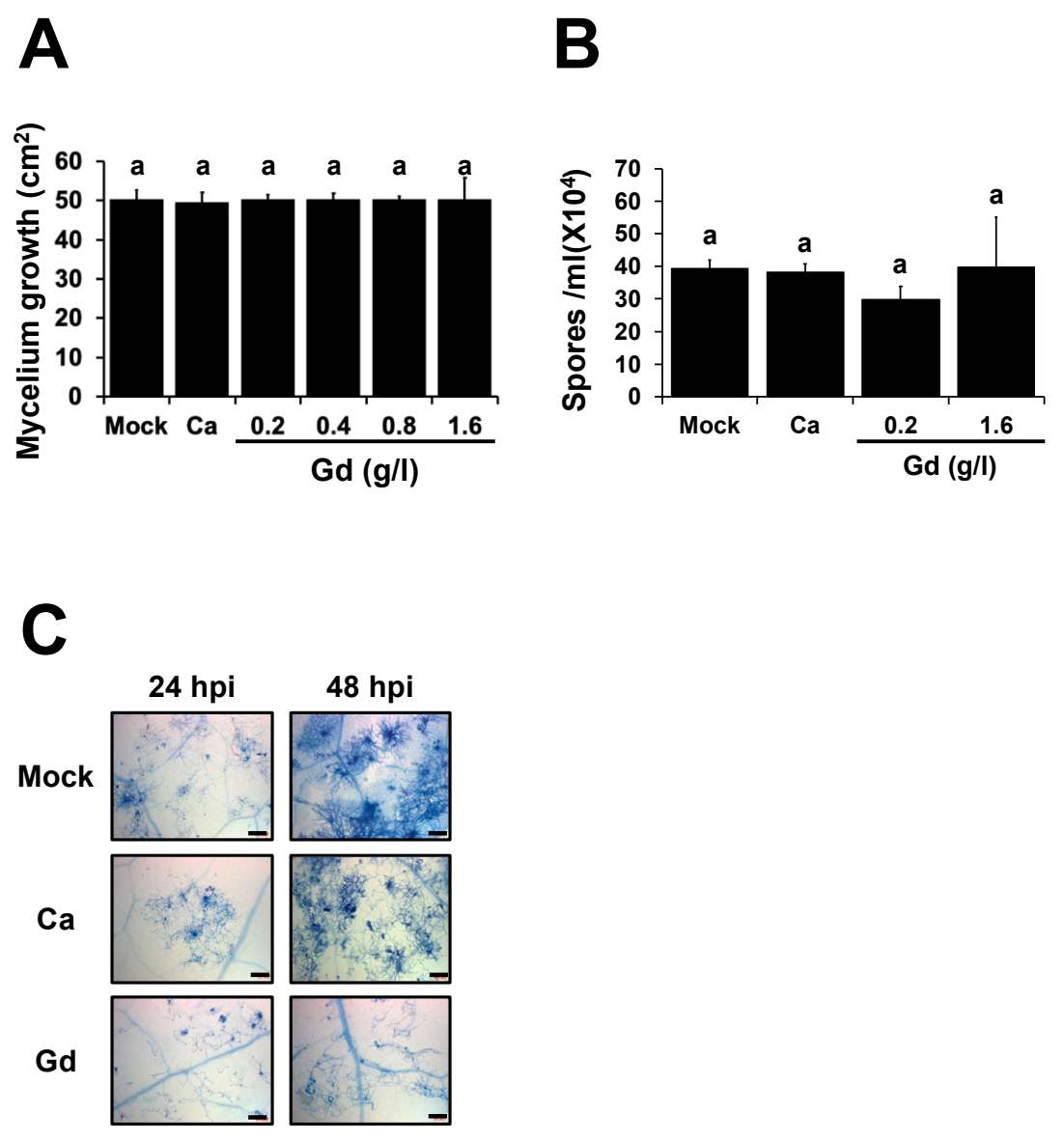

Figure 2. Gd does not affect the growth and development of B. cinerea. (A) A total of $5 \mu \mathrm{L}$ of spore suspension of $B$. cinerea $\left(5 \times 10^{4}\right.$ spores $\left.\mathrm{mL}^{-1}\right)$ was placed on the center of the Petri dish containing PDA supplemented with water (mock), $0.2 \mathrm{~g} / \mathrm{L} \mathrm{Ca}$, and the indicated concentrations of Gd and incubated at $22^{\circ} \mathrm{C}$. Growth inhibition was evaluated by measuring the diameter of the mycelium on the dish 3 days post inoculation. (B) Spores produced by B. cinerea 10 days after growth on a Petri dish containing PDA supplemented with mock, $0.2 \mathrm{~g} / \mathrm{L} \mathrm{Ca}$, and the indicated concentrations of Gd were isolated and quantified as previously described [33]. (C) B. cinerea development over $A$. thaliana-infected leaves was determined by trypan blue staining at 24 and 48 hpi. Representative images were selected as a visual illustration from two independent experiments. Bars represent mean values $( \pm$ SD) of three independent experiments. Scale bar $=200 \mu \mathrm{m}$. Different letters above each bar represent statistically significant differences according to the Scott-Knott test $(p<0.05)$.

To evaluate for how long $\mathrm{Gd}$ can protect $A$. thaliana plants against $B$. cinerea, different pre-treatment times were analyzed by measuring the lesion size at $72 \mathrm{hpi}$. Interestingly, the Ca-treated control plants showed a significant reduction in lesion size at 48,72 , and $96 \mathrm{hpt}$ of approximately $30 \%$ compared to 24 and $120 \mathrm{hpt}$, suggesting that Ca has an effect on the plant-pathogen interaction at these time points (Figure 3B). Nevertheless, at all the time points analyzed, Gd-treated plants always showed a significant reduction in lesion size compared to their corresponding control Ca-treated samples, fluctuating between $60 \%$ (24 and $120 \mathrm{hpt}$ ) and $40 \%(48,72$, and $96 \mathrm{hpt}$ ) (Figure 3B). Thus, these results indicate that $\mathrm{Gd}$ exerts a protective effect against $B$. cinerea over several days. 


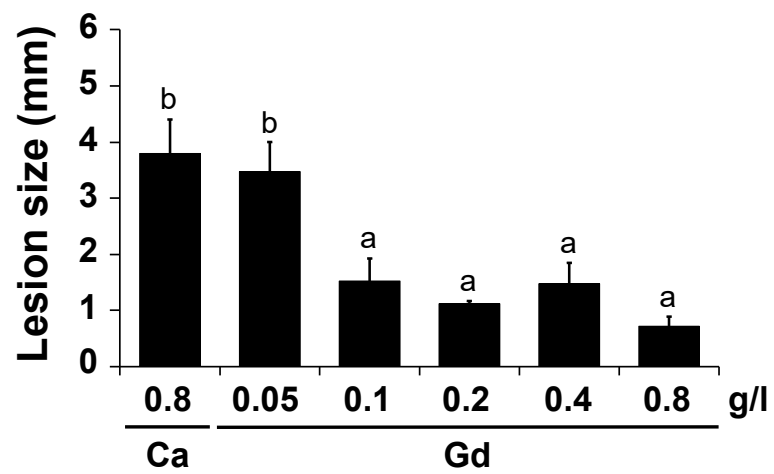

B

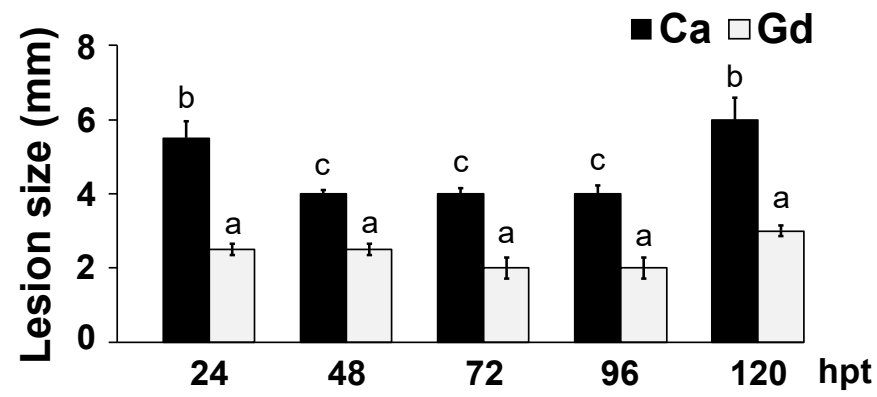

Figure 3. Gd-induced protection against $B$. cinerea is dose-dependent and long-lasting. (A) Four-weekold A. thaliana plants were pre-treated for $24 \mathrm{~h}(24 \mathrm{hpt})$ with the indicated Gd concentration or $0.8 \mathrm{~g} / \mathrm{L}$ of $\mathrm{Ca}$. After this, $3 \mu \mathrm{L}$ droplets containing a B. cinerea spore suspension $\left(5 \times 10^{4}\right.$ spores $\left.\mathrm{mL}^{-1}\right)$ were applied and infection symptoms were evaluated at 72 hpi by measuring lesion size. (B) Four-week-old A. thaliana plants were sprayed until saturation with $0.2 \mathrm{~g} / \mathrm{L}$ of Ca or Gd for 24, 48, 72, 96, or 120 (hpt); after these times, $3 \mu \mathrm{L}$ droplets containing $B$. cinerea spore suspension $\left(5 \times 10^{4}\right.$ spores $\left.\mathrm{mL}^{-1}\right)$ were applied and infection symptoms were evaluated at $72 \mathrm{hpi}$ by measuring lesion size. Bars represent mean values $( \pm \mathrm{SD})$ of three independent experiments $(n=30$ for each experiment). Different letters above each bar represent statistically significant differences according to the Scott-Knott test $(p<0.05)$.

\subsection{Gd Triggers a Systemic Defense Response to B. cinerea}

To further characterize the Gd-induced plant defenses against B. cinerea, we analyzed whether a systemic protection was activated (Figure 4). Firstly, half of the rosette leaves from 4-week-old $A$. thaliana plants were pre-treated with $0.2 \mathrm{~g} / \mathrm{L}$ of $\mathrm{Gd}$ or $\mathrm{Ca}$ (local) and the other half with $\mathrm{H}_{2} \mathrm{O}$ (systemic). Then, at $24 \mathrm{hpt}$ we inoculated all the leaves with B. cinerea spores and measured the lesion size at $72 \mathrm{hpi}$. Plants treated with Gd showed a strong reduction in the lesion sizes for both tissues (local and systemic) compared to their respective Ca-treated control leaves (Figure 4A). In another tray, 4-week-old $A$. thaliana plants were watered to saturation with a solution of $0.2 \mathrm{~g} / \mathrm{L}$ of $\mathrm{Gd}$ or Ca and untreated leaves were inoculated for $24 \mathrm{hpt}$ with B. cinerea and the lesion size measured at $72 \mathrm{hpi}$. Gd-watered plants showed an approximately $50 \%$ reduction in lesion size compared to the Ca-watered control plants (Figure 4B). These results indicate that Gd induces a systemic defense response against $B$. cinerea in $A$. thaliana plants. 
A

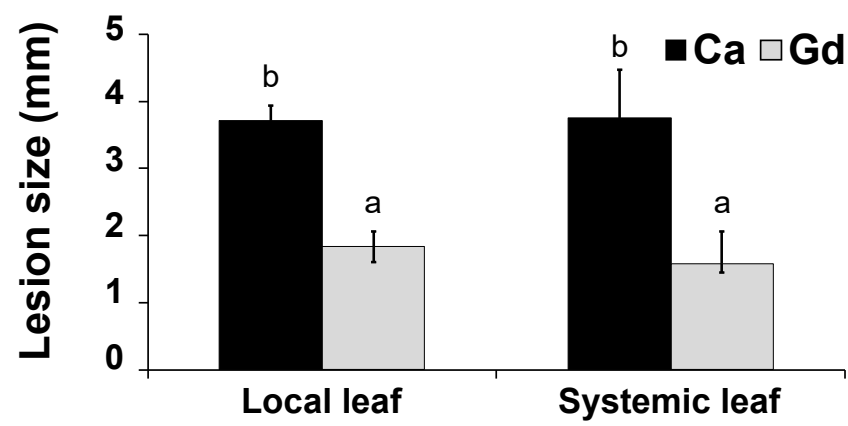

B

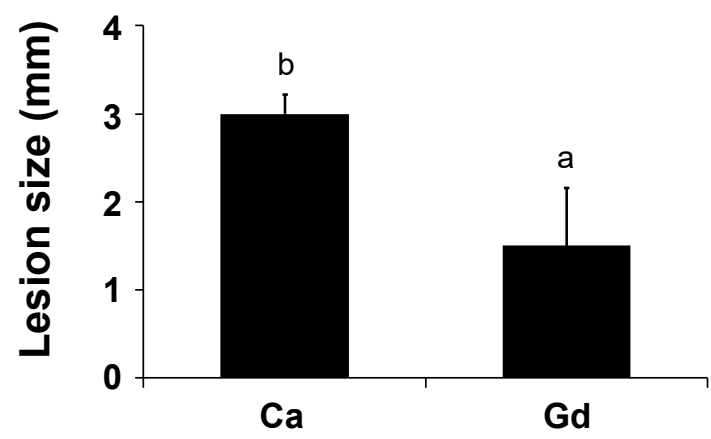

Figure 4. Systemic effect induced by Gd against B. cinerea in A. thaliana plants. Four-week-old A. thaliana plants were pre-treated as follows: (A) half of the rosette leaves were pre-treated with $0.2 \mathrm{~g} / \mathrm{L} \mathrm{Gd}$ or $\mathrm{Ca}$ (local) and the other half with $\mathrm{H}_{2} \mathrm{O}$ (systemic); (B) plants were watered until saturation with $0.2 \mathrm{~g} / \mathrm{L}$ of $\mathrm{Gd}$ or Ca. At $24 \mathrm{hpt}, 3 \mu \mathrm{L}$ droplets containing B. cinerea spore suspension $\left(5 \times 10^{4}\right.$ spores $\left.\mathrm{mL}^{-1}\right)$ were applied. Infection symptoms were evaluated at $72 \mathrm{hpi}$ by measuring lesion size. Bars represent mean values $( \pm S D)$ of three independent experiments $(n=30$ for each experiment). Different letters above each bar represent statistically significant differences according to the Scott-Knott test $(p<0.05)$.

\subsection{Gd Does Not Modify the Cuticle Permeability but Triggers a ROS Burst}

We have described that cuticle-related mutants, as part of a defensive syndrome, showing an increase in leaf permeability and a rapid induction of the plant innate immunity, including the accumulation of reactive oxygen species (ROS) and resistance against $B$. cinerea [34,35]. In order to determine if the Gd-triggered defense responses against B. cinerea are mediated by a similar syndrome, we quantified the leaf permeability using three different methods: measuring the efflux of chlorophyll, toluidine blue staining, and calcofluor staining, as previously described [33]. Four-week-old A. thaliana plants were treated for $24 \mathrm{~h}$ with $0.2 \mathrm{~g} / \mathrm{L}$ of $\mathrm{Gd}$ or Ca. Leaf permeability was not modified by exogenous Gd application, since no differences were observed between Ca- and Gd-treated samples in any of the methods used (Figure S2). Then, using a similar treatment, we quantified the presence of ROS at 0, 3, 6, 12, and 24 hpt (Figure 5) through histological analysis and densitometric quantification with the probe 5-(and-6)-carboxy-2,7-dichlorodihydrofluorescein diacetate (DCF-DA), which detects a broad spectrum of ROS. Histological analysis showed that, at $3 \mathrm{hpt}$, a strong accumulation of ROS induced by Gd (Figure 5A) was already detected and further maintained without significant changes up to $24 \mathrm{hpt}$, while with Ca-treated plants ROS was not induced at any of the time points (Figure 5A). These observations were confirmed by densitometric quantification (Figure 5B). Taken together, these 
results suggest that the ROS burst detected after Gd application was induced directly by Gd treatment rather than by a modification of the cuticle permeability.

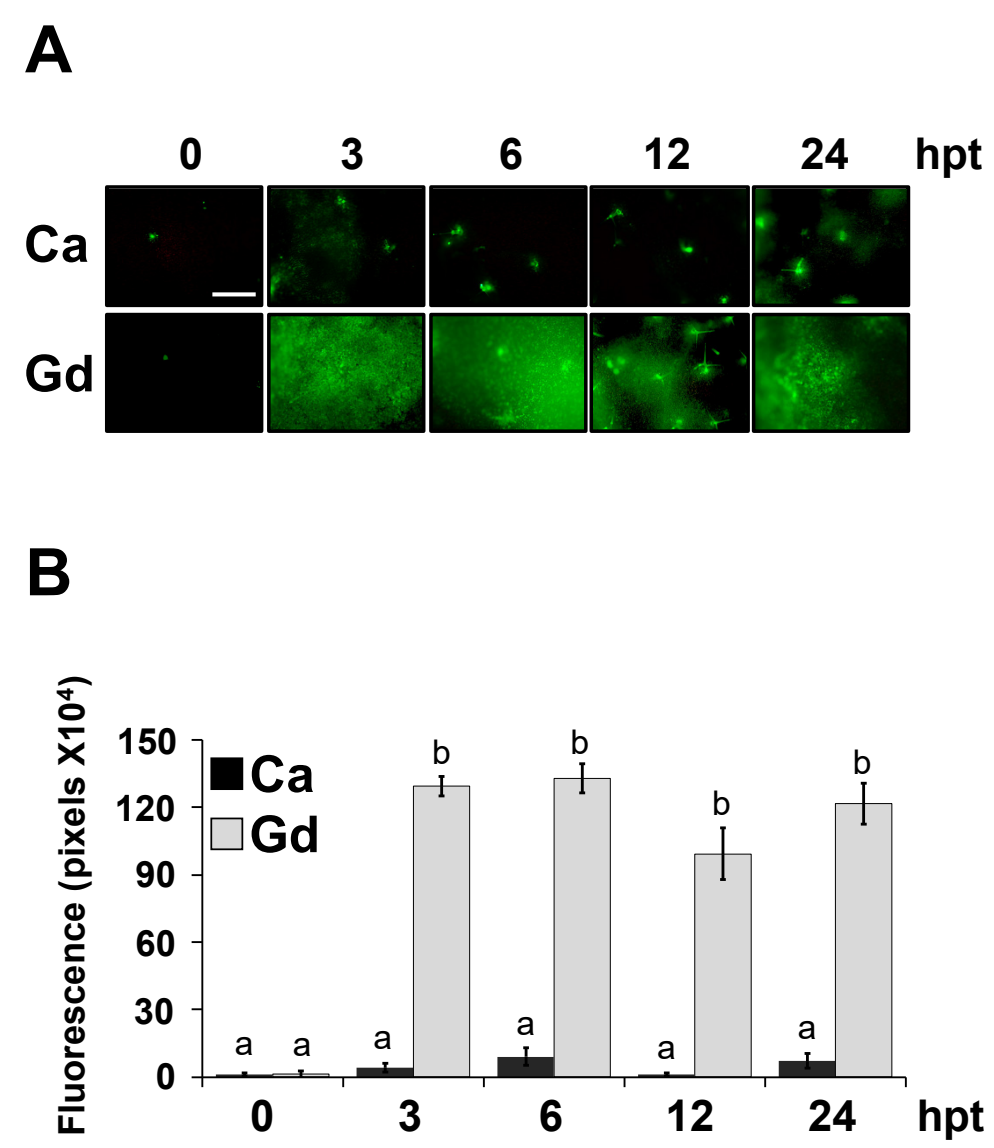

Figure 5. Gd-induced accumulation of ROS. (A) Leaves from 4-week-old A. thaliana plants treated with $0.2 \mathrm{~g} / \mathrm{L}$ of Ca or Gd were stained using DCF-DA to detect basal ROS levels at the indicated time point (B) Densitometric quantification of ROS production at indicated time points after Ca or Gd treatment. Bars represent the mean values $( \pm S D)$ of three independent experiments $(n=30)$. Different letters above each bar represent statistically significant differences according to the Scott-Knott test $(p<0.05)$. Scale bar $=200 \mu \mathrm{m}$.

\subsection{Gadolinium Up-Regulates the Responses to Biotic Stimulus and Represses the Responses to} Abiotic Stimulus

To identify the genetic elements that participate in Gd-induced responses, we studied the transcriptional changes in the Gd-treated plants using a genome-wide RNA sequencing analysis (RNA-seq). Total RNA was isolated from 4-week-old $A$. thaliana plants at two different time points-first at $24 \mathrm{hpt}$ with $0.2 \mathrm{~g} / \mathrm{L}$ of Gd or Ca and then from plants at $24 \mathrm{hpi}$ inoculated with B. cinerea (Figure 6). Gd-pretreated plants showed 1189 and 200 genes with significantly higher and lower expressions, respectively, compared to the Ca-induced ones (Figure 6A; Supplementary Data 1). Gd-treated plants that were infected with B. cinerea showed 673 and 433 genes with higher or lower expressions, respectively, compared to $\mathrm{Ca}$ treated plants (Figure 6B; Supplementary Data 2). These results suggest that the application of exogenous Gd modifies the transcriptome to improve the growth and defense responses of A. thaliana. 
A

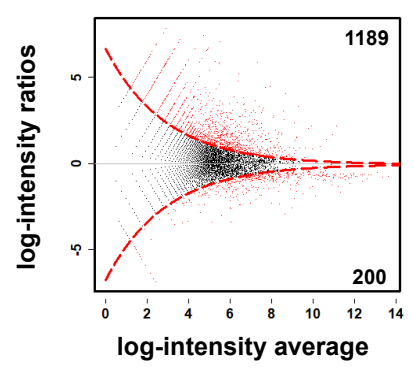

C

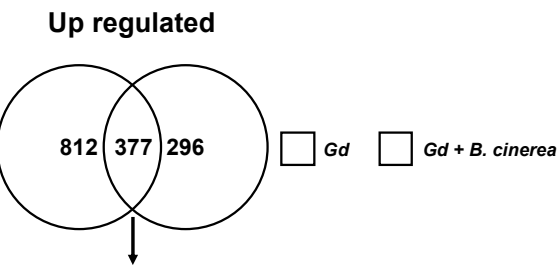

GO terms classified

into defense response

D

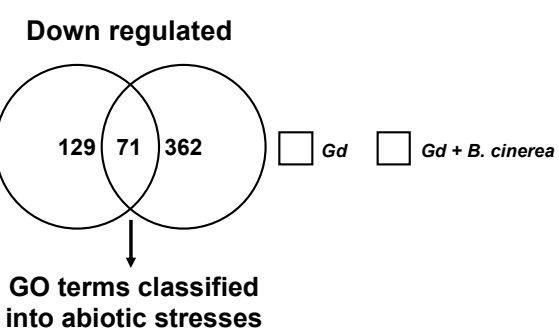

Figure 6. RNAseq analysis of Gd-induced A. thaliana plants. Five 4-week-old $A$. thaliana plants were sprayed until saturation with $0.2 \mathrm{~g} / \mathrm{L}$ of $\mathrm{Ca}$ or $\mathrm{Gd}(24 \mathrm{hpt})$ and then infected with B. cinerea (24 hpi). Total RNA for each condition, from three independent experiments, was pooled and sequenced (RNA-seq). (A) MA plot of Gd- versus Ca-treated samples at 24 hpt. (B) MA plot of Gd- versus Ca-treated samples infected with B. cinerea at 24 hpi. The red points represent DEGs ( $p$-value $<0.05)$, while black dots indicate genes with a similar expression. The dotted red line shows the limit between similarly and differentially expressed genes. The black horizontal line at zero provides a visual check for symmetry. Venn diagrams representing overlapping or non-overlapping gene sets of up-regulated DEGs (C) and down-regulated genes (D), respectively, were identified in $A$. thaliana plants induced with $0.2 \mathrm{~g} / \mathrm{L}$ of $\mathrm{Ca}$ or $\mathrm{Gd}$ and infected with B. cinerea, as indicated.

From the DEGs detected in the Gd application conditions compared to Ca (Table S1), we wanted to identify those that had higher and lower expressions after the infection by B. cinerea took place. A total of 377 induced genes and 71 repressed genes follow this pattern (Figure 6C,D). Interestingly, the GO analysis of these DEGs revealed that almost all the genes with a higher expression were classified into the defense response mechanisms, including responses to fungi and innate immune responses (Table S1). In contrast, the repressed genes were classified mostly in the category of responses to abiotic stresses (Table S1). These results suggest that different sets of mechanisms are induced or repressed by $\mathrm{Gd}$ application. 


\subsection{Plant Defense Response Genes Are Induced by Gadolinium Treatment and during the Interaction with B. cinerea}

The transcriptional activation of the defense responses induced by $\mathrm{Gd}$ was analyzed using the bioinformatics tool MapMan [36]. From this analysis, an induction of the responses to biotic stress was observed in Gd-pretreated plants (24 hpt) (Figure S3A) and Gd-induced plants later infected with B. cinerea (24 hpi) (Figure S3B). A list of candidate genes that have been characterized as improving the resistance against $B$. cinerea was recently described [10]. We analyzed the accumulation of these candidate transcripts in Gd-induced plants $(24 \mathrm{hpt})$ and the plants after the interaction with the pathogen ( $24 \mathrm{hpi})$ in comparation to Ca-treated samples (Figure 7A). Eight out of 13 genes were induced at $24 \mathrm{hpt}$, while 10 were up-regulated at $24 \mathrm{hpi}$, suggesting that $\mathrm{Gd}$ transcriptionally induces defense responses against $B$. cinerea. To further confirm and validate the genome-wide RNA sequencing analysis (Supplementary Data 1 and 2), we further characterized by qRT-PCR the accumulation of transcripts of representative $A$. thaliana genes previously described to be involved in the plant-microbe interactions from the ROS-(ZAT12) [37], SA-(ICS1 and PR1) [38,39], JA-(PDF1.2) [40], and ET-signaling pathways (ACS6 and PR4) [41,42]. This was conducted in 4-week-old $A$. thaliana plants pretreated with $\mathrm{H}_{2} \mathrm{O}$ (mock), $\mathrm{Ca}$, or $\mathrm{Gd}$ (24 hpt) (Figure 7B). Remarkably, we determined that the mock- and Ca-treated samples showed similar expression patterns for all the genes, confirming the validity of the $\mathrm{Ca}$ control. On the other hand, we observed that at $24 \mathrm{hpt}$, all the analyzed genes were induced in Gd-treated plants compared to the Ca-induced ones. It is worth mentioning that for all the genes analyzed, the expression signatures were similar to those detected by RNAseq (highlighted in Supplementary Data 1). Additionally, based on the structural similarities between $\mathrm{Gd}$ and $\mathrm{Ca}$, one might expect that $\mathrm{Ca}$-induced genes will be also up-regulated by $\mathrm{Gd}$. In agreement with this, several Ca-responsive genes were part of the Gd-induced ones, such as the calcium-binding EF-hand family protein (AT3G01830) and the vacuolar calcium-binding protein-related (AT1G62480) (Supplementary Data 1), validating our analysis. Taken together, these results suggest that application of $\mathrm{Gd}$ transcriptionally activates the selected ROS-, SA-, JA-, and ET-induced defense response genes that were previously identified as part of the plant defense mechanisms against $B$. cinerea $[33,43]$.

\subsection{Gd-Induced Defense Response Against B. cinerea Is Dependent of JA and ET}

As part of the defense response against $B$. cinerea, the plant transcriptome is modified, including the activation of ROS-, SA-, ET-, ABA-, JA-, and ET-induced signaling pathways [45]. In this work, we show that Gd transcriptionally induces ROS-, SA-, JA-, and ET-induced defense response genes (Figure 7). In order to determine the effect of each response pathway on Gd-triggered defenses, we analyzed mutants impaired in ROS, SA, $\mathrm{JA}$, and ET accumulation. Measuring the disease incidence and lesion size, we determined that plants were still protected against $B$. cinerea after $\mathrm{Gd}$ application in the mutants of NADPH oxidase D (AtrbohD) and $F(A t r b o h F)$ involved in ROS production (Figure 8A,B). On the other hand, even the SA-deficient mutant eds 5 showed a slight increase in disease incidence and lesion size after $\mathrm{Gd}$ application, although these changes were not statistically significant compared to those in Col-0 wt-treated plants (Figure 8A,B). However, for the ET- and JA-related mutants ethylene-insensitive 3 (ein3), jasmonate-amido synthetase (jar1), and lipoxygenase 2 (lox2), we observed a similar disease incidence and lesion sizes in Gd-induced plants compared to the Ca-treated samples, suggesting that the Gd-induced defense response is mediated by JA and ET (Figure 8A,B). To confirm this observation, we selected the genes from our transcriptomic analysis that had been previously described to be involved in ET- and JA-related responses that have also been characterized to be involved in resistance to B. cinerea [46], and we analyzed their differential accumulation status (Figure 8C,D). For ET-related genes, 60\% were induced at $24 \mathrm{hpt}$ with $\mathrm{Gd}$, while $30 \%$ were up-regulated after the interaction with the pathogen took place (24 hpi, Figure 8C). On the other hand, for JA-related genes $78 \%$ were induced after the treatment with Gd (24hpt) and $48 \%$ kept this expression pattern after the interaction with B. cinerea (24 hpi) 
(Figure 8D). Taken together, these results indicated that the Gd-triggered defense response against $B$. cinerea is mostly dependent on the JA/ET-induced responses.

\begin{tabular}{|c|c|c|c|}
\hline & & & $\frac{24}{\text { hpt hpi }}$ \\
\hline WRKY33 & Pathogen-induced defense signaling & AT2G38470 & \\
\hline OCP3 & Callose deposition & AT5G11270 & \\
\hline$P G I P 1 / 2$ & Endo-PG inhibitor & AT5G06860 & \\
\hline FOU2 & Depolarization-activated $\mathrm{Ca}+2$ channel & AT4G03560 & \\
\hline RST1 & Lipid synthesis & AT3G27670 & \\
\hline ERF1 & $\mathrm{JA}$ and $\mathrm{ET}$ signaling & АT3G23240 & \\
\hline OPR3 & JA biosynthesis & AT2G06050 & \\
\hline MYC2/JIN1 & Jasmonate-insensitive & AT1G32640 & \\
\hline WAK1 & A signaling receptor of OGs & AT1G21250 & \\
\hline ААОЗ-2 & ABA biosynthesis & AT2G27150 & \\
\hline ABA2-12 & ABA biosynthesis & AT1G52340 & \\
\hline AB/5 & ABA insensitive & AT2G36270 & \\
\hline EXLA2 & Cell wall extensibility & AT4G38400 & \\
\hline
\end{tabular}

B

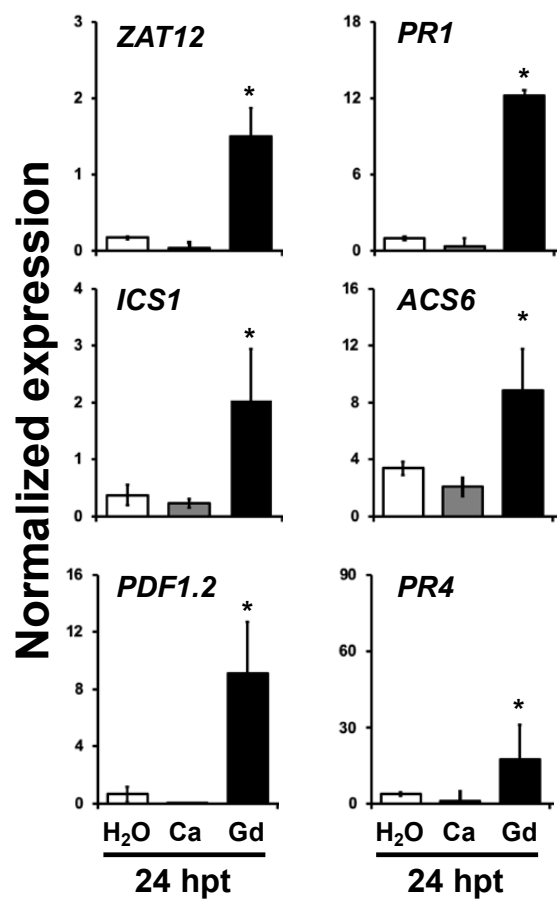

Figure 7. Gd transcriptionally activate the plant defense response genes. (A) Heatmaps of the expression $\log 2$-fold changes of genes previously described to be involved in the resistance against B. cinerea [10], compared to the corresponding controls, from RNAseq data at $24 \mathrm{hpt}$ and hpi. (B) Fourweek-old $A$. thaliana plants pretreated with $\mathrm{H}_{2} \mathrm{O}$ (mock), $0.2 \mathrm{~g} / \mathrm{L} \mathrm{Ca}$, or Gd (24 hpt). Quantitative real-time PCR (qRT-PCR) expression analysis of ZAT12, ICS1, PR1, ACS6, PDF1.2, and PR4 was determined and normalized with respect to the mean of two reference genes AT4G26410 and AT1G72150, as previously described $[43,44]$. A representative experiment with three technical replicates is shown $( \pm \mathrm{SE})$. Three independent experiments were carried out with similar results. Asterisk above each bar represents statistically significant differences to the mock-treated samples according to the Student's T-test $(p<0.05)$. 

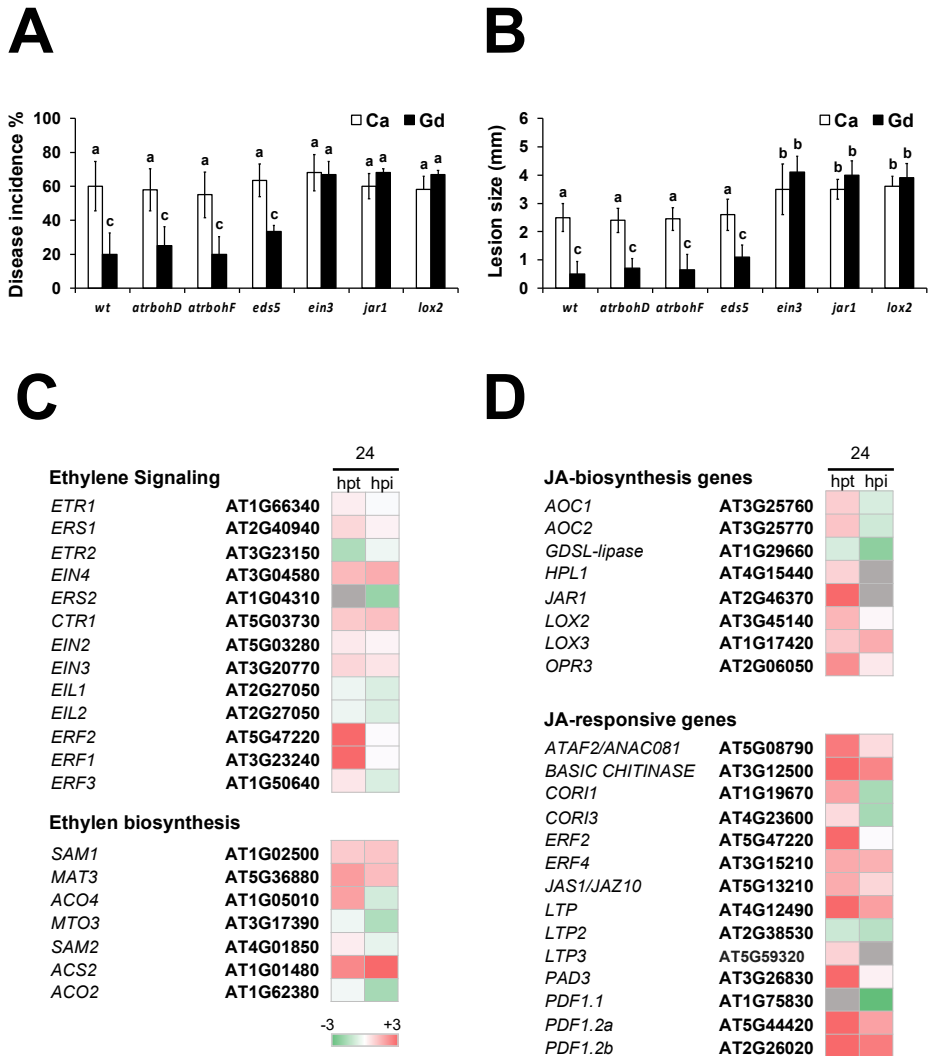

D

\begin{tabular}{|c|c|c|}
\hline \multicolumn{3}{|r|}{24} \\
\hline \multicolumn{2}{|c|}{ JA-biosynthesis genes } & \\
\hline$A O C 1$ & АT3G25760 & \\
\hline AOC2 & AT3G25770 & \\
\hline GDSL-lipase & AT1G29660 & \\
\hline HPL1 & AT4G15440 & \\
\hline JAR1 & AT2G46370 & \\
\hline LOX2 & AT3G45140 & \\
\hline LOX3 & AT1G17420 & \\
\hline OPR3 & AT2G06050 & \\
\hline \multicolumn{3}{|c|}{ JA-responsive genes } \\
\hline ATAF2/ANAC081 & АТ5G08790 & \\
\hline BASIC CHITINASE & AT3G 12500 & \\
\hline COR/1 & AT1G19670 & \\
\hline COR/3 & AT4G23600 & \\
\hline ERF2 & AT5G47220 & \\
\hline ERF4 & AT3G15210 & \\
\hline JAS1/JAZ10 & AT5G13210 & \\
\hline LTP & AT4G12490 & \\
\hline LTP2 & AT2G38530 & \\
\hline LTP3 & AT5G59320 & \\
\hline PAD3 & AT3G26830 & \\
\hline PDF1.1 & AT1G75830 & \\
\hline PDF1.2a & AT5G44420 & \\
\hline PDF1.2b & AT2G26020 & \\
\hline PDF1.2c & AT5G44430 & \\
\hline SAG13 & AT2G29350 & \\
\hline VSP2 & AT5G24770 & \\
\hline
\end{tabular}

Figure 8. Role of ROS, SA, and JA in Gd-induced resistance to B. cinerea in A. thaliana. The AtrbohD, AtrbohF, eds5, ein3, jar1, and lox2 mutants were evaluated. (A) Four-week-old $A$. thaliana plants were sprayed until saturation with $0.2 \mathrm{~g} / \mathrm{L}$ of $\mathrm{Ca}$ or $\mathrm{Gd}$. After $24 \mathrm{hpt}, 3 \mu \mathrm{L}$ droplets containing a B. cinerea spore suspension $\left(5 \times 10^{4}\right.$ spores $\left.\mathrm{mL}^{-1}\right)$ were applied and disease incidence was determined by measuring the percentage of plants showing disease symptoms at $72 \mathrm{hpi}$. (B) The disease severity was determined by measuring the lesion size of all the infected leaves. Heatmaps of the expression of log2-fold changes in ET- (C) and JA-related genes (D), compared to the corresponding controls, from RNAseq data at $24 \mathrm{hpt}$ and hpi. Bars represent mean values $( \pm \mathrm{SD})$ of three independent experiments $(n=50)$. Different letters above each bar represent statistically significant differences according to the Scott-Knott test $(p<0.05)$.

\section{Discussion}

3.1. A Transcriptome Analysis Provides New Insights into the Molecular Mechanisms Involved in the Gd Response in A. thaliana

During the last 30 years, REEs have been widely used as biostimulants in the farmlands of China and other countries $[47,48]$. Previous physiological analyses indicated that the exogenous application of REEs modifies calcium-induced responses, such as the structure and function of the cytoplasmic membranes, photosynthesis, the modulation of hormone metabolism, and the increased efficiency of water use [48]. Nevertheless, their modes of action(s), in particular at the transcriptional level and during biotic interactions, are still poorly understood [49]. In this report, we show that $A$. thaliana treated with gadolinium $(\mathrm{Gd})$ protected the plants against $B$. cinerea (Figure 1 ). In order to uncover the molecular mechanisms behind this effect, we performed a genome-wide transcriptional analysis (Supplementary Data 1). The GO analysis revealed that almost all the induced genes were classified into the defense response mechanisms, while the repressed ones were classified mostly in response to abiotic stresses (Figure 6). Interestingly, several processes which had been previously associated with changes in root growth were identified among 
the repressed DEGs, including responses to abscisic acid (ABA) and water deprivation. High concentrations of ABA have been shown to inhibit root growth [50], while water deficiency stimulates it [51]. These reports support the view that the information generated in this work can be used as a starting point to unravel the molecular mechanisms behind REE-induced responses, potentially leading to the optimization of their application as biostimulants.

\subsection{Gd Is a Novel Biocontrol against the Broad Host-Range Necrotrophic Fungus B. cinerea}

One of the limiting factors in food production is disease caused by fungi [52], with B. cinerea being one of the major ones responsible for these losses [2]. Most of the treatments to control the infections inflicted by this pathogen are based on the application of synthetic fungicides. However, an increase in worldwide regulatory policies and the claim to reduce their application due to the possible harmful side effects have led to searches for new eco-friendly alternatives, such as biostimulants. Despite the generalized use of REEs as biostimulants in agriculture, only a few reports have studied its impacts on plantmicrobe interactions [27-29], and to our knowledge none have described the inhibition or modification of the interaction with $B$. cinerea. Here, we show that $\mathrm{Gd}$ can protect $A$. thaliana plants against $B$. cinerea by inducing defense responses. We also show that even at high Gd concentrations, the growth and development of $B$. cinerea is not affected by $\mathrm{Gd}$ or Ca under in vitro or in planta conditions (Figure 2). This is somewhat unexpected, since REEs have been described as inhibiting the development of other microorganisms, and high concentrations of $\mathrm{CaCl}_{2}$ can decrease the spore germination and mycelial growth of B. cinerea [53]. These results suggest that the protective effect induced by $\mathrm{Gd}$ is mediated by the modification of the plant defense mechanisms rather than a direct inhibitory effect on the pathogen. Additionally, we determined that the Gd-induced protection is dosedependent and lasts for 5 days (Figure 3). All these results indicate that Gd has the potential to be used as a biocontrol against this agronomically important pathogen.

3.3. Gd Induces Protection against B. cinerea by Activating Early and Late Defense Responses, in Particular the JA- and ET-Induced Signaling Pathway

Our RNA-seq analysis shows that early and late defense responses are transcriptionally induced after the application of Gd (Table S1). As part of the early defense mechanisms, plants can trigger innate immunity, which includes the accumulation of reactive oxygen species (ROS), calcium $\left(\mathrm{Ca}^{2+}\right)$ influx, protein phosphorylation, MAPK-dependent signaling cascades, and the transcriptional induction of defense response genes $[7,8]$. In this work, we observed a fast accumulation of intracellular ROS after Gd application (3 hpt), which was further maintained for $24 \mathrm{~h}$ (Figure 5). This is consistent with the fact that we have described a direct link between ROS accumulation and the resistance to $B$. cinerea in previous studies $[33,34,54]$. This could be sufficient to explain the reduction in infection observed in Gd-treated plants. However, it is necessary to mention that other REEs have been evidenced to modify ROS accumulation [55]. Additionally, we determined that mutants of the enzymes AtrbohD and AtrbohF, involved in intracellular ROS production, can still be protected after Gd treatment (Figure 8), suggesting that either only intracellular ROS is produced or that other genes are probably implicated in Gd-induced ROS production. It would be interesting to test this hypothesis using mutants deficient in extracellular ROS production. Based on this information, we cannot discard the idea that the ROS burst might be triggered specifically by Gd or as a general response to incubation with REEs, and can only assume that this is part of the defense mechanism against $B$. cinerea.

The activation of innate immunity is followed by secondary mechanisms, including the induction of SA-, JA-, and ET-dependent signaling pathways, finally leading to the activation of systemic acquired resistance (SAR) in non-infected distal parts of the plant $[6,11,12]$. We revealed that SA-, JA-, and ET-induced genes were transcriptionally activated after Gd treatment and during the interaction with B. cinerea (Figure 7 and Supplementary Data 1 and 2). However, we observed that the mutant impaired in SA accumulation (eds5) shows a slight, but not statistically significant, reduction in Gd-induced protection. The protection 
induced by this REE was completely lost in ein 3 , jar1, and lox2 mutants, which are impaired in JA- and ET-induced responses (Figure 8). SA-triggered defense responses have been reported to be involved against necrotrophic pathogens in A. thaliana [56,57] and tobacco [58]. However, other studies have reported that $A$. thaliana defense responses against $B$. cinerea depend mostly on JA and ET [59-61]. Our results indicate that the protective effect of Gd against this pathogen depends on ET- and JA-dependent signaling pathways.

\subsection{Ca might Elicit the Defense Responses but Not as Strongly as Gd}

To cope with environmental stresses, plant responses are intimately coordinated by the complex signaling networks of the so called "trio signaling" messengers: ROS, electrical signals, and calcium [62]. In particular, Ca plays an important role in plant-pathogen interactions, since once an attack is perceived its intracellular concentration is rapidly increased, activating defense responses in a local and systemic fashion [63]. As mentioned, the physiological changes induced by REEs have been related to their structural chemical resemblance to calcium [20]. In agreement, Gd has been described to elicit a similar signaling pathway to this secondary messenger [64]. In this report, in order to reduce the expected phenotypes induced by the structural and functional resemblance of $\mathrm{Gd}$ and $\mathrm{Ca}$, we used calcium nitrate as a control. Ca has been described to inhibit the spore germination and mycelial growth of $B$. cinerea [53]. Nevertheless, we did not detect a reduction in infection due to $B$. cinerea on $A$. thaliana plants treated with $\mathrm{Ca}$ (Figure $1 \mathrm{~B}, \mathrm{C}$ ) either locally or systemically at this concentration (Figure 4). However, interestingly, during the timecourse experiment, we observed a significant reduction in lesion size after 48,72, and $96 \mathrm{hpt}$ in Ca-induced samples, compared to at $24 \mathrm{hpt}$ in Ca-treated plants (Figure 3B). This reduction, however, was never as strong as that measured in Gd-treated plants at any of the time points analyzed (Figure 3B). This result suggests that both $\mathrm{Ca}$ and $\mathrm{Gd}$ might elicit defense responses, though at different times, against the necrotrophic pathogen $B$. cinerea. A detailed analysis of the Ca-induced defense mechanisms after 48, 72, and $96 \mathrm{hpt}$ and of all the DEGs identified in this work might help us to uncover and understand the potential differences between Ca- and Gd-induced defense pathways.

Finally, even if our initial goal was to characterize the effect of Gd on B. cinerea, it is worth mentioning that our RNA-seq analysis suggests that this REE might extend its effect over other biotic and abiotic stresses. Among the biological processes induced by Gd treatment, several defense responses were identified, including responses to other organisms, such as bacteria and response to salicylic acid (SA). For instance, the SAinduced signaling pathway is a central part of the plant defense responses to multiple pathogens, including infections by viruses, bacteria, and fungi [65]. On the other hand, our GO analysis revealed that repressed genes were classified mostly in response to abiotic stimuli, including responses to abscisic acid (ABA) and water deprivation. REEs have been described to increase plant resistance to different abiotic stresses $[17,66]$. With this in mind, our results seem to point towards a possible use of $\mathrm{Gd}$ in the context of sustainable agricultural production to enhance plant tolerance to numerous biotic and abiotic stresses. Nevertheless, to continue using $\mathrm{Gd}$ as a plant stimulator it will be necessary to take into account that long-term use might increase its potential as a source of pollution in the soil, as previously described for other REEs [67].

\section{Materials and Methods}

\subsection{Plant Material and Growth Conditions}

Arabidopsis thaliana (L.), Heynh ecotype Columbia-0 (Col-0), and lox2 mutant were obtained from the Nottingham Arabidopsis Stock Centre (Nottingham, UK). The A. thaliana mutants used in this work (all in the Col-0 background) were the following: AtrbohD, AtrbohF [68], eds5 [69] jar1 [70], and ein3 [71]. Plants grown under in vitro conditions were generated from surface-sterilized seeds germinated in square Petri dishes containing Murashige and Skoog (MS) media supplemented with $0.8 \%$ agar and $1 \%$ sucrose. Plates were kept at $4{ }^{\circ} \mathrm{C}$ for two days and incubated vertically at $21^{\circ} \mathrm{C}$ for 10 days in a growth 
chamber with a $16 \mathrm{~h}$ light $/ 8 \mathrm{~h}$ dark photoperiod. For ex vitro experiments, $A$. thaliana seeds were grown on a pasteurized (applying heat until the mix reaches $82{ }^{\circ} \mathrm{C}$ for $30 \mathrm{~min}$ ) soil mix of humus/perlite (3:1), kept at $4{ }^{\circ} \mathrm{C}$ for two days, and then transferred to the growth chamber. Plants were grown for 4 weeks in a $12 \mathrm{~h}$ light/12 h dark cycle with a $60-70 \%$ relative humidity, a light intensity of $200 \mu \mathrm{mol} / \mathrm{m}^{2} / \mathrm{s}$, a day temperature of $20-22{ }^{\circ} \mathrm{C}$, and a night temperature of $16-18{ }^{\circ} \mathrm{C}$. For in vitro experiments, surface-sterilized $A$. thaliana seeds were incubated for $1 \mathrm{~h}$ in distilled sterile water (mock), $0.2 \mathrm{~g} / \mathrm{L}(0.0012 \mathrm{M})$ calcium nitrate $\left(\mathrm{Ca}\left(\mathrm{NO}_{3}\right)_{2}\right)$, or $0.2 \mathrm{~g} / \mathrm{L}(0.00044 \mathrm{M})$ gadolinium (III) nitrate hexahydrate $\left(\mathrm{Gd}\left(\mathrm{NO}_{3}\right)_{3} \cdot 6 \mathrm{H}_{2} \mathrm{O}\right)$. Seeds were germinated as described above and the germination rate, primary root length, and fresh and dry weight were measured 10 days post germination.

\subsection{Gadolinium Treatment and B. cinerea Plant Inoculation}

Four-week-old $A$. thaliana plants were pre-treated by spraying to the point of run off with $0.2 \mathrm{~g} / \mathrm{L}$ of gadolinium (III) nitrate hexahydrate, $0.2 \mathrm{~g} / \mathrm{L}$ of calcium nitrate, or $\mathrm{H}_{2} \mathrm{O}$ for $24,48,72,96$, or $120 \mathrm{~h}$ post-treatment, hpt. After this time, $3 \mu \mathrm{L}$ droplets of $B$. cinerea spore suspension $\left(5 \times 10^{4}\right.$ spores $\left.\mathrm{mL}^{-1}\right)$ were applied. The procedures of $B$. cinerea infection, including disease incidence and measurement of lesion size, were determined $72 \mathrm{~h}$ postinfection (hpi), as previously described [33]. For the dose-response assay, plants were pre-treated for $24 \mathrm{~h}(24 \mathrm{hpt})$ with the indicated concentration of gadolinium (III) nitrate hexahydrate or calcium nitrate and then infected with B. cinerea and evaluated at $72 \mathrm{hpi}$.

\subsection{Systemic Defense Response Analysis}

For the systemic assay, two methodologies were used: (i) half of the rosette leaves of 4-week-old $A$. thaliana plants were pre-treated by spraying with $0.2 \mathrm{~g} / \mathrm{L}$ of gadolinium(III) nitrate hexahydrate or calcium nitrate (local) and the other half with $\mathrm{H}_{2} \mathrm{O}$ (systemic) and (ii) 4-week-old $A$. thaliana plants were pre-treated (watering the soil until saturation) with $0.2 \mathrm{~g} / \mathrm{L}$ of gadolinium(III) nitrate hexahydrate or calcium nitrate for $24 \mathrm{~h}(24 \mathrm{hpt})$. For both conditions, leaves were infected with $B$. cinerea and evaluated at $72 \mathrm{hpi}$, as described above.

\subsection{In Planta B. cinerea Growth Analysis}

Fungal hyphae were stained and plant cell death assayed as previously described [72] Once stained, leaves were imbibed in $20 \%$ glycerol for $1 \mathrm{~h}$ and observed using a microscope with bright-field settings. Representative images were selected as a visual illustration.

\subsection{In Vitro Inhibitory Assay of B. cinerea Growth}

The $B$. cinerea strain BMM (originally isolated from grape wine) was provided by Brigitte Mauch-Mani (University of Neuchatel, Switzerland). B. cinerea in vitro growth and preparation of spore suspension were performed as previously described [33]. For the inhibition assay, $5 \mu \mathrm{L}$ of a spore suspension of $B$. cinerea $\left(5 \times 10^{4}\right.$ spores $\left.\mathrm{mL}^{-1}\right)$ was placed at the center of a Petri dish containing potato dextrose agar media (PDA) supplemented with $0.2 \mathrm{~g} / \mathrm{L}$ of calcium nitrate or $0.2,0.4,0.8$, or $1.6 \mathrm{~g} / \mathrm{L}$ of gadolinium(III)nitrate hexahydrate, as indicated in the figure legends. The plates were incubated at $22^{\circ} \mathrm{C}$ for 3 days and then the diameter of the mycelial growth was determined using Image J version 1.51 (U. S. National Institutes of Health, Bethesda, MD, USA), as previously described [73]. Ten days post incubation, B. cinerea spores were collected from the plates and re-suspended in $5 \mathrm{~mL}$ of $\mathrm{H}_{2} \mathrm{O}$ and quantified using a Neubauer cell counting chamber.

\subsection{Cuticle Permeability Analysis}

We recently described that cuticle-related mutants show an increase in leaf permeability and a rapid induction of plant innate immunity, including the accumulation of reactive oxygen species (ROS) $[34,35]$. To determine the cuticle permeability, three methods were used: (i) calcofluor white staining, (ii) toluidine blue staining, and (iii) chlorophyll extraction and quantification $[33,34,54]$. To stain with calcofluor white, leaves were bleached in absolute ethanol overnight, equilibrated in $0.2 \mathrm{M} \mathrm{NaPO}_{4}(\mathrm{pH}$ 9) for $1 \mathrm{~h}$, and incu- 
bated for $1 \mathrm{~min}$ in $0.5 \%$ calcofluor white in $0.2 \mathrm{M} \mathrm{NaPO}_{4}(\mathrm{pH}$ 9). Leaves were rinsed in $\mathrm{NaPO}_{4}$ buffer to remove excess calcofluor white and were viewed under a UV light. Toluidine blue staining was carried out by placing $6 \mu \mathrm{L}$ droplets on the leaf surface of $0.025 \%$ toluidine blue solution dissolved in $\frac{1}{4}$ PDB. After incubation for $2 \mathrm{~h}$, the leaves were washed gently with distilled water to remove excess solution from them. Representative images were selected as a visual illustration. For chlorophyll extraction and quantification, leaves were weighed and immersed in $30 \mathrm{~mL}$ of $80 \%$ ethanol. Chlorophyll suspension was sampled in the dark at room temperature with gentle agitation at 2, 5, 10, 20, 30, 40, 50, 60, and $120 \mathrm{~min}$ after immersion. The chlorophyll content was determined by measuring the absorbance at 664 and $647 \mathrm{~nm}$ and the micromolar concentration of total chlorophyll per gram of fresh weight of tissue was calculated using the following equation: $\left(7.93 \times\left(\mathrm{A}_{664} \mathrm{~nm}\right)+19.53 \times\left(\mathrm{A}_{647} \mathrm{~nm}\right)\right) \mathrm{g}^{-1}$ fresh weight.

\subsection{Detection of ROS}

ROS were detected using the fluorescent probe 5-(and-6)-carboxy-2,7-dichlorodihydrofluorescein diacetate (DCF-DA), as previously described [33]. Representative images were selected as a visual illustration.

\subsection{RNA Extraction and Genome-Wide Transcriptomic Analysis}

For the three independent experiments, leaves from $5 \mathrm{~A}$. thalian a plants were harvested, pooled and immediately frozen in liquid nitrogen and kept at $-80^{\circ} \mathrm{C}$. Two conditions were analyzed. The first was at $24 \mathrm{hpt}$ with $0.2 \mathrm{~g} / \mathrm{L}$ of gadolinium(III)nitrate hexahydrate or calcium nitrate and the second was from plants pre-treated by spraying the entire leaf with gadolinium(III)nitrate hexahydrate $(24 \mathrm{hpt}$ ) or calcium nitrate and infected for $24 \mathrm{hpi}$ with $B$. cinerea by spraying the spore suspension all over the leaf. Total RNA was extracted as described in the manufacturer's protocols using the Spectrum ${ }^{\mathrm{TM}}$ Plant total RNA Kit (Sigma Aldrich, San Luis, MO, USA). The integrity of the extracted RNA was measured by agarose gel electrophoresis (1.2\%). The NanoDrop 2000/2000c (Thermo Fisher Scientific, Waltham, MA, USA) was used to calculate concentrations and purity. Samples used for RNA-seq were also analyzed using an Agilent 2100 Bioanalyzer (Agilent Genomics, Santa Clara, CA, USA). RNA-seq libraries were prepared following the manufacturer's instructions from isolated total RNA using the Illumina TruSeq RNA Sample Preparation Kit (Illumina, San Diego, CA, USA). The libraries were sequenced using the manufacturer's protocol of the Illumina GAIIx platform for 72 paired-end cycles. Sequences are publicly available through the Gene Expression Omnibus database under the accession number GSE123522. Contamination and adapter removal were carried out using in-house Perl scripts. Fastq sequences were filtered based on quality (FASTQ Quality Filter v0.0.6, Q 33, http:/ /hannonlab.cshl.edu/fastx_toolkit/index.html) and mapped to the A. thaliana transcriptome (TAIR10) using Bowtie2 [74]. Gene expression was determined using RSEM v1.3 [75] and compared between the RNA-seq libraries using DEGseq v3.6 [76] and the FPKM data from RSEM. Only transcripts with a Log2 fold change of $<-1$ or $>1$ with a $p$-value $<0.05$ were considered. DEGs identified by genome-wide transcriptomic analysis were analyzed and classified into gene ontology classes (GO) using the PANTHER Gene List Analysis tools and default parameters. The identification of commonly regulated DEGs was performed using the software FiRe ver. 2.2, as previously described [77]. The MapMan software was used to visualize the amplitudes of the changes in the expression of individual genes in diagrams of cellular processes, as previously described [36].

\subsection{Quantitative Real Time RT-PCR}

The pooled total RNA $(1.0 \mu \mathrm{g})$ used for RNAseq analysis was retro-transcribed into cDNA according to the manufacturer's indications using the SCRIPT cDNA Synthesis Kit (Jena Bioscience, Jena, Germany). qRT-PCR was performed in 96-well plates with the Applied Biosystems StepOne ${ }^{\mathrm{TM}}$ and StepOnePlus ${ }^{\mathrm{TM}}$ Real-Time PCR System (ThermoFisher Scientific, Waltham, MA, USA) using the SYBR Green Maxima SYBR Green/ROX qPCR 
Master Mix (2X) (ThermoFisher Scientific, Waltham, MA, USA). Three independent experiments were analyzed, each with three technical replicates. The qRT-PCR conditions were as follows: an initial $95^{\circ} \mathrm{C}$ denaturation step for $5 \mathrm{~min}$, followed by denaturation for $15 \mathrm{~s}$ at $95^{\circ} \mathrm{C}$, annealing for $30 \mathrm{~s}$ at $60^{\circ} \mathrm{C}$, and extension for $30 \mathrm{~s}$ at $72{ }^{\circ} \mathrm{C}$ for 45 cycles. Gene expression values were normalized using the mean expression of two genes: AT4G26410 (RHIP1) and AT1G72150 (PATL1), which were previously described as stable reference genes [44,78]. Normalized gene expression was determined using the comparative $2^{-\Delta \Delta C \mathrm{~T}}$ method, as previously described [79]. Primers for gene expression analysis have been previously described: for PR1, PDF1.2 and PR4 [43]; for ZAT12 [37], ICS1 [80] and ACS6 [81].

\subsection{Statistical Analysis}

All results are reported as mean values $( \pm \mathrm{SD})$ and were analyzed by an analysis of variance and compared by the Scott-Knott test $(p<0.05)$ using the software GraphPad Prism version 8.1.0 (2019, GraphPad Software, San Diego, CA, USA). All the data analyzed were obtained from three independent experiments.

Supplementary Materials: The following are available online at https:/ /www.mdpi.com/article/10 .3390/ijms22094938/s1, Supplementary Table S1: GO enrichment analysis of differentially expressed genes commonly induced or repressed after Gd application $(24 \mathrm{hpt})$ and during the interaction with B. cinerea (24 hpi), Supplementary Figure S1: Gd does not affect germination rates, fresh nor dry weight, Supplementary Figure S2: Gd does not modify plant cuticle permeability, Supplementary Figure S3: MapMan pathway analysis of differentially expressed genes of (A) 24 hpt with $0.2 \mathrm{gL}^{-1}$ $\mathrm{Gd}$ and (B) afterwards infected with with B. cinereal (24 hpi) compared to Ca-treated samples, Supplementary Data 1: List of significantly differentially expressed genes $24 \mathrm{hpt}$, Supplementary Data 2: List of significantly differentially expressed genes $24 \mathrm{hpi}$.

Author Contributions: D.F., A.T., K.R.F.S.-E. and M.S. conceived and designed the experiments. J.S.B.-O., D.F., M.T., W.A., Y.J.R.-C. and I.M.-L. performed the experiments. D.F., A.T. and M.S. wrote and revised the paper. All authors have read and agreed to the published version of the manuscript.

Funding: J.S.B.-O. and K.R.F.S.-E. are supported by Conselho Nacional de Desenvolvimento Científico e Tecnológico (CNPq) and Coordenação de Aperfeiçoamento de Pessoal de Nivel Superior (Capes), Brazil. W.A. and Y.J.R.-C. acknowledge the fellowship, No. 240087 and No. 745733, from Consejo Nacional de Ciencia y Tecnología (CONACYT), México. IM-L acknowledges a post-doctoral fellowship from Dirección General de Asuntos del Personal Académico-UNAM no. CJIC/CTIC/1077/2018. This work was supported by funds from Dirección General de Asuntos del Personal Académico-UNAM (PAPIIT), grants IA202620, IA200816 and IN203720 to D.F., A.T. and M.S., respectively. As well as the Ciencias Básicas grant from CONACYT No. 253494 and No. A1-S-16129 to A.T. and D.F., respectively.

Institutional Review Board Statement: Not applicable.

Informed Consent Statement: Not applicable.

Data Availability Statement: Sequences are publicly available through the Gene Expression Omnibus database under the accession number GSE123522.

Acknowledgments: We thank Antony Buchala and Michael F. Dunn for critical reading and comments of the manuscript. We thank the next-generation sequencing core facility of the Institute of Biotechnology-UNAM for their technical support. Thanks are also extended to Valdecir Biondo for his critical comments.

Conflicts of Interest: The authors declare no conflict of interest.

\section{References}

1. Nunes, C.A. Biological control of postharvest diseases of fruit. Eur. J. Plant Pathol. 2012, 133, 181-196. [CrossRef]

2. Barkai-Golan, R. Chapter 2-Postharvest disease initiation. In Postharvest Diseases of Fruits and Vegetables; Elsevier: Amsterdam, The Netherlands, 2001; pp. 3-24.

3. Dean, R.; Van Kan, J.A.L.; Pretorius, Z.A.; Hammond-Kosack, K.E.; Di Pietro, A.; Spanu, P.D.; Rudd, J.J.; Dickman, M.; Kahmann, R.; Ellis, J.; et al. The Top 10 fungal pathogens in molecular plant pathology. Mol. Plant Pathol. 2012, 13, 414-430. [CrossRef]

4. Du Jardin, P. Plant biostimulants: Definition, concept, main categories and regulation. Sci. Hortic. 2015, 196, 3-14. [CrossRef] 
5. Yakhin, O.I.; Lubyanov, A.A.; Yakhin, I.A.; Brown, P.H. Biostimulants in Plant Science: A Global Perspective. Front. Plant Sci. 2017, 7, 2049. [CrossRef]

6. Boller, T.; Felix, G. A Renaissance of Elicitors: Perception of Microbe-Associated Molecular Patterns and Danger Signals by Pattern-Recognition Receptors. Annu. Rev. Plant Biol. 2009, 60, 379-406. [CrossRef]

7. Tsuda, K.; Somssich, I.E. Transcriptional networks in plant immunity. New Phytol. 2015, 206, 932-947. [CrossRef]

8. Katagiri, F.; Tsuda, K. Understanding the Plant Immune System. Mol. Plant Microbe Interact. 2010, 23, 1531-1536. [CrossRef]

9. Mengiste, T.; Laluk, K.; AbuQamar, S. Mechanisms of induced resistance against B. cinerea. In Postharvest Pathology; Prusky, D., Gullino, M.L., Eds.; Springer: Dordrecht, The Netherlands, 2010; pp. 13-30.

10. AbuQamar, S.; Moustafa, K.; Tran, L.S. Mechanisms and strategies of plant defense against Botrytis cinerea. Crit. Rev. Biotechnol. 2017, 37, 262-274. [CrossRef]

11. Robert-Seilaniantz, A.; Grant, M.; Jones, J.D.G. Hormone Crosstalk in Plant Disease and Defense: More Than Just JASMONATESALICYLATE Antagonism. Annu. Rev. Phytopathol. 2011, 49, 317-343. [CrossRef]

12. Maruri-López, I.; Aviles-Baltazar, N.Y.; Buchala, A.; Serrano, M. Intra and Extracellular Journey of the Phytohormone Salicylic Acid. Front. Plant Sci. 2019, 10, 423. [CrossRef]

13. Chien, S.S. Peculiar Effects of Barium, Strontium, and Cerium on Spirogyra. Bot. Gaz. 1917, 63, 406-409. [CrossRef]

14. Hu, Z.; Richter, H.; Sparovek, G.; Schnug, E. Physiological and Biochemical Effects of Rare Earth Elements on Plants and Their Agricultural Significance: A Review. J. Plant Nutr. 2004, 27, 183-220. [CrossRef]

15. Kerstin, R. Rare Earth Elements in Agriculture with Emphasis on Animal Husbandry. Ph.D. Thesis, Ludwig-MaximiliansUniversität München, Munich, Germany, 2006.

16. Wang, L.; Cheng, M.; Chu, Y.; Li, X.; Chen, D.D.Y.; Huang, X.; Zhou, Q. Responses of plant calmodulin to endocytosis induced by rare earth elements. Chemosphere 2016, 154, 408-415. [CrossRef]

17. Kovarikova, M.; Tomaskova, I.; Soudek, P. Rare earth elements in plants. Biol. Plant 2019, 63, 20-32. [CrossRef]

18. Zhang, C.; Li, Q.; Zhang, M.; Zhang, N.; Li, M. Effects of rare earth elements on growth and metabolism of medicinal plants. Acta Pharm. Sin. B 2013, 3, 20-24. [CrossRef]

19. Jia, Y.; Chunyan, L.; Guozheng, Q.; Kaoshan, C. The Effect of Nd (3+) and Burdock Oligosaccharide on the Germination of Cassia obtusifolia Seeds. Chin. Agric. Sci. Bull. 2008, 11.

20. Brown, P.H.; Rathjen, A.H.; Graham, R.D.; Tribe, D.E. Chapter 92 Rare earth elements in biological systems. In Handbook on the Physics and Chemistry of Rare Earths; Elsevier: Amsterdam, The Netherlands, 1990; Volume 13, pp. 423-452.

21. Thomas, P.J.; Carpenter, D.; Boutin, C.; Allison, J.E. Rare earth elements (REEs): Effects on germination and growth of selected crop and native plant species. Chemosphere 2014, 96, 57-66. [CrossRef]

22. Ismail, A.; Riemann, M.; Nick, P. The jasmonate pathway mediates salt tolerance in grapevines. J. Exp. Bot. 2012, 63, 2127-2139. [CrossRef]

23. Qiao, F.; Chang, X.-L.; Nick, P. The cytoskeleton enhances gene expression in the response to the Harpin elicitor in grapevine. J. Exp. Bot. 2010, 61, 4021-4031. [CrossRef]

24. Lu, C.; Tian, H. Global nitrogen and phosphorus fertilizer use for agriculture production in the past half century: Shifted hot spots and nutrient imbalance. Earth Syst. Sci. Data 2017, 9, 181-192. [CrossRef]

25. Val'kov, A.V.; Stepanov, S.I.; Sergievskii, V.V.; Chekmarev, A.M. Monazite raw material for the production of highly effective fertilizers. Theor. Found. Chem. Eng. 2010, 44, 497-499. [CrossRef]

26. Sabiha, J.; Waheed, S.; Siddique, N.; Shakoor, R.; Tufail, M. Measurement of rare earths elements in Kakul phosphorite deposits of Pakistan using instrumental neutron activation analysis. J. Radioanal. Nucl. Chem. 2010, 284, 397-403. [CrossRef]

27. Adisa, I.O.; Reddy Pullagurala, V.L.; Rawat, S.; Hernandez-Viezcas, J.A.; Dimkpa, C.O.; Elmer, W.H.; White, J.C.; Peralta-Videa, J.R.; Gardea-Torresdey, J.L. Role of Cerium Compounds in Fusarium Wilt Suppression and Growth Enhancement in Tomato (Solanum lycopersicum). J. Agric. Food Chem. 2018, 66, 5959-5970. [CrossRef]

28. Guohong, W.; Yucai, C. Study on the application of rare earths to rubber trees. In New Frontiers in Rare Earth Science and Applications; Guangxian, X., Jimei, X., Eds.; Academic Press: Cambridge, MA, USA, 1985; p. 1510.

29. Majumdar, S.; Peralta-Videa, J.R.; Bandyopadhyay, S.; Castillo-Michel, H.; Hernandez-Viezcas, J.-A.; Sahi, S.; Gardea-Torresdey, J.L. Exposure of cerium oxide nanoparticles to kidney bean shows disturbance in the plant defense mechanisms. J. Hazard. Mater. 2014, 278, 279-287. [CrossRef] [PubMed]

30. Batista-Oliveira, J.S. Elementos Terras Raras na Indução de Resistência em Soja. Ph.D. Thesis, Universidade Estadual de Maringá, Maringá, Brazil, 2018.

31. Zhang, H.; Feng, J.; Zhu, W.; Liu, C.; Gu, J. Bacteriostatic effects of cerium-humic acid complex. Biol. Trace Elem. Res. 2000, 73, 29-36. [CrossRef]

32. Zhang, J.; Cheng, H.; Gao, Q.; Zhang, Z.; Liu, Q. Effect of lanthanum on growth and biochemical property of Sclerotinia sclerotiorum. Chin. J. Appl. Ecol. 2000, 11, 382-384.

33. L'Haridon, F.; Besson-Bard, A.; Binda, M.; Serrano, M.; Abou-Mansour, E.; Balet, F.; Schoonbeek, H.-J.; Hess, S.; Mir, R.; Léon, J.; et al. A Permeable Cuticle Is Associated with the Release of Reactive Oxygen Species and Induction of Innate Immunity. PLoS Pathog. 2011, 7, e1002148. [CrossRef] 
34. Blanc, C.; Coluccia, F.; L’Haridon, F.; Torres, M.; Ortiz-Berrocal, M.; Stahl, E.; Reymond, P.; Schreiber, L.; Nawrath, C.; Métraux, J.-P.; et al. The Cuticle Mutant eca2 Modifies Plant Defense Responses to Biotrophic and Necrotrophic Pathogens and Herbivory Insects. Mol. Plant Microbe Interact. 2018, 31, 344-355. [CrossRef]

35. Aragón, W.; Reina-Pinto, J.J.; Serrano, M. The intimate talk between plants and microorganisms at the leaf surface. J. Exp. Bot. 2017, 68, 5339-5350. [CrossRef]

36. Thimm, O.; Bläsing, O.; Gibon, Y.; Nagel, A.; Meyer, S.; Krüger, P.; Selbig, J.; Müller, L.A.; Rhee, S.Y.; Stitt, M. mapman: A user-driven tool to display genomics data sets onto diagrams of metabolic pathways and other biological processes. Plant J. 2004, 37, 914-939. [CrossRef] [PubMed]

37. Rizhsky, L.; Davletova, S.; Liang, H.; Mittler, R. The Zinc Finger Protein Zat12 Is Required for Cytosolic Ascorbate Peroxidase 1 Expression during Oxidative Stress in Arabidopsis. J. Biol. Chem. 2004, 279, 11736-11743. [CrossRef]

38. Wildermuth, M.C.; Dewdney, J.; Wu, G.; Ausubel, F.M. Isochorismate synthase is required to synthesize salicylic acid for plant defence. Nature 2001, 417, 562-565. [CrossRef]

39. Uknes, S.; Mauch-Mani, B.; Moyer, M.; Potter, S.; Williams, S.; Dincher, S.; Chandler, D.; Slusarenko, A.; Ward, E.; Ryals, J. Acquired resistance in Arabidopsis. Plant Cell 1992, 4, 645.

40. Manners, J.M.; Penninckx, I.A.; Vermaere, K.; Kazan, K.; Brown, R.L.; Morgan, A.; Maclean, D.J.; Curtis, M.D.; Cammue, B.P.; Broekaert, W.F. The promoter of the plant defensin gene PDF1.2 from Arabidopsis is systemically activated by fungal pathogens and responds to methyl jasmonate but not to salicylic acid. Plant Mol. Biol. 1998, 38, 1071-1080. [CrossRef] [PubMed]

41. Arteca, J.M.; Arteca, R.N. A multi-responsive gene encoding 1-aminocyclopropane-1-carboxylate synthase (ACS6) in mature Arabidopsis leaves. Plant Mol. Biol. 1999, 39, 209-219. [CrossRef] [PubMed]

42. Kravchuk, Z.; Vicedo, B.; Flors, V.; Camañes, G.; González-Bosch, C.; García-Agustín, P. Priming for JA-dependent defenses using hexanoic acid is an effective mechanism to protect Arabidopsis against B. cinerea. J. Plant Physiol. 2011, 168, 359-366. [CrossRef] [PubMed]

43. Hael-Conrad, V.; Abou-Mansour, E.; Díaz-Ricci, J.C.; Métraux, J.P.; Serrano, M. The novel elicitor AsES triggers a defense response against Botrytis cinerea in Arabidopsis thaliana. Plant Sci. 2015, 241, 120-127. [CrossRef]

44. Serrano, M.; Guzman, P. Isolation and Gene Expression Analysis of Arabidopsis thaliana Mutants with Constitutive Expression of ATL2, an Early Elicitor-Response RING-H2 Zinc-Finger Gene. Genetics 2004, 167, 919-929. [CrossRef]

45. Windram, O.; Madhou, P.; McHattie, S.; Hill, C.; Hickman, R.; Cooke, E.; Jenkins, D.J.; Penfold, C.A.; Baxter, L.; Breeze, E.; et al. Arabidopsis Defense against Botrytis cinerea: Chronology and Regulation Deciphered by High-Resolution Temporal Transcriptomic Analysis. Plant Cell Online 2012, 24, 3530-3557. [CrossRef]

46. Méndez-Bravo, A.; Calderón-Vázquez, C.; Ibarra-Laclette, E.; Raya-González, J.; Ramírez-Chávez, E.; Molina-Torres, J.; GuevaraGarcía, A.A.; López-Bucio, J.; Herrera-Estrella, L. Alkamides Activate Jasmonic Acid Biosynthesis and Signaling Pathways and Confer Resistance to Botrytis cinerea in Arabidopsis thaliana. PLoS ONE 2011, 6, e27251. [CrossRef]

47. Pang, X.; Li, D.; Peng, A. Application of rare-earth elements in the agriculture of China and its environmental behavior in soil. Environ. Sci. Pollut. Res. 2002, 9, 143. [CrossRef] [PubMed]

48. Tyler, G. Rare earth elements in soil and plant systems-A review. Plant Soil 2004, 267, 191-206. [CrossRef]

49. Yang, Q.; Wang, L.; Zhou, Q.; Huang, X. Toxic effects of heavy metal terbium ion on the composition and functions of cell membrane in horseradish roots. Ecotoxicol. Environ. Saf. 2015, 111, 48-58. [CrossRef] [PubMed]

50. Luo, X.; Chen, Z.; Gao, J.; Gong, Z. Abscisic acid inhibits root growth in Arabidopsis through ethylene biosynthesis. Plant J. 2014, 79, 44-55. [CrossRef]

51. Hsiao, T.C.; Xu, L.K. Sensitivity of growth of roots versus leaves to water stress: Biophysical analysis and relation to water transport. J. Exp. Bot. 2000, 51, 1595-1616. [CrossRef]

52. Fisher, M.C.; Henk, D.A.; Briggs, C.J.; Brownstein, J.S.; Madoff, L.C.; McCraw, S.L.; Gurr, S.J. Emerging fungal threats to animal, plant and ecosystem health. Nature 2012, 484, 186. [CrossRef]

53. Sasanuma, I.; Suzuki, T. Effect of calcium on cell-wall degrading enzymes of Botrytis cinerea. Biosci. Biotechnol. Biochem. 2016, 80, 1730-1736. [CrossRef]

54. Benikhlef, L.; L’Haridon, F.; Abou-Mansour, E.; Serrano, M.; Binda, M.; Costa, A.; Lehmann, S.; Metraux, J.-P. Perception of soft mechanical stress in Arabidopsis leaves activates disease resistance. BMC Plant Biol. 2013, 13, 133. [CrossRef]

55. Liu, D.; Zheng, S.; Wang, X. Lanthanum regulates the reactive oxygen species in the roots of rice seedlings. Sci. Rep. 2016, 6, 31860. [CrossRef]

56. Govrin, E.M.; Levine, A. Infection of Arabidopsis with a necrotrophic pathogen, Botrytis cinerea, elicits various defense responses but does not induce systemic acquired resistance (SAR). Plant Mol. Biol. 2002, 48, 267-276. [CrossRef]

57. Halim, V.A.; Altmann, S.; Ellinger, D.; Eschen-Lippold, L.; Miersch, O.; Scheel, D.; Rosahl, S. PAMP-induced defense responses in potato require both salicylic acid and jasmonic acid. Plant J. 2009, 57, 230-242. [CrossRef] [PubMed]

58. Menard, R.; Alban, S.; de Ruffray, P.; Jamois, F.; Franz, G.; Fritig, B.; Yvin, J.-C.; Kauffmann, S. beta-1,3 Glucan Sulfate, but Not beta-1,3 Glucan, Induces the Salicylic Acid Signaling Pathway in Tobacco and Arabidopsis. Plant Cell 2004, 16, $3020-3032$. [CrossRef] [PubMed]

59. Thomma, B.P.H.J.; Penninckx, I.A.M.A.; Broekaert, W.F.; Cammue, B.P.A. The complexity of disease signaling in Arabidopsis. Curr. Opin. Immunol. 2001, 13, 63-68. [CrossRef] 
60. Glazebrook, J. Contrasting mechanisms of defense against biotrophic and necrotrophic pathogens. Annu. Rev. Phytopathol. 2005, 43, 205-227. [CrossRef] [PubMed]

61. Ferrari, S.; Plotnikova, J.M.; De Lorenzo, G.; Ausubel, F.M. Arabidopsis local resistance to Botrytis cinerea involves salicylic acid and camalexin and requires EDS4 and PAD2, but not SID2, EDS5 or PAD4. Plant J. 2003, 35, 193-205. [CrossRef]

62. Choi, W.-G.; Miller, G.; Wallace, I.; Harper, J.; Mittler, R.; Gilroy, S. Orchestrating rapid long-distance signaling in plants with Ca2+, ROS and electrical signals. Plant J. 2017, 90, 698-707. [CrossRef]

63. Toyota, M.; Spencer, D.; Sawai-Toyota, S.; Jiaqi, W.; Zhang, T.; Koo, A.J.; Howe, G.A.; Gilroy, S. Glutamate triggers long-distance, calcium-based plant defense signaling. Science 2018, 361, 1112. [CrossRef] [PubMed]

64. Rincon-Zachary, M.; Teaster, N.D.; Sparks, J.A.; Valster, A.H.; Motes, C.M.; Blancaflor, E.B. Fluorescence Resonance Energy Transfer Sensitized Emission of Yellow Cameleon 3.60 Reveals Root-Zone-Specific Calcium Signatures in Arabidopsis in Response to Aluminum and Other Trivalent Cations. Plant Physiol. 2010. [CrossRef]

65. Klessig, D.F.; Choi, H.W.; Dempsey, D.M.A. Systemic Acquired Resistance and Salicylic Acid: Past, Present, and Future. Mol. Plant Microbe Interact. 2018, 31, 871-888. [CrossRef]

66. Liu, D.; Wang, X.; Chen, Z. Effects of rare earth elements and REE-binding proteins on physiological responses in plants. Protein Pept. Lett. 2012, 19, 198-202. [CrossRef]

67. Todorovsky, D.S.; Minkova, N.L.; Bakalova, D.P. Effect of the application of superphosphate on rare earths' content in the soil. Sci. Total Environ. 1997, 203, 13-16. [CrossRef]

68. Torres, M.A.; Dangl, J.L.; Jones, J.D.G. Arabidopsis gp91phox homologues AtrbohD and AtrbohF are required for accumulation of reactive oxygen intermediates in the plant defense response. Proc. Natl. Acad. Sci. USA 2002, 99, 517-522. [CrossRef]

69. Nawrath, C.; Métraux, J.-P. Salicylic Acid Induction-Deficient Mutants of Arabidopsis Express PR-2 and PR-5 and Accumulate High Levels of Camalexin after Pathogen Inoculation. Plant Cell 1999, 11, 1393.

70. Chassot, C.; Nawrath, C.; Metraux, J.P. Cuticular defects lead to full immunity to a major plant pathogen. Plant J. 2007, 49, 972-980. [CrossRef] [PubMed]

71. Roman, G.; Lubarsky, B.; Kieber, J.J.; Rothenberg, M.; Ecker, J.R. Genetic analysis of ethylene signal transduction in Arabidopsis thaliana: Five novel mutant loci integrated into a stress response pathway. Genetics 1995, 139, 1393-1409. [CrossRef] [PubMed]

72. Fernández-Bautista, N.; Domínguez-Núñez, J.A.; Moreno, M.M.C.; Berrocal-Lobo, M. Plant Tissue Trypan Blue Staining During Phytopathogen Infection. Bio Protoc. 2016, 6, e2078. [CrossRef]

73. Ferreira-Saab, M.; Formey, D.; Torres, M.; Aragón, W.; Padilla, E.A.; Tromas, A.; Sohlenkamp, C.; Schwan-Estrada, K.R.F.; Serrano, M. Compounds Released by the Biocontrol Yeast Hanseniaspora opuntiae Protect Plants Against Corynespora cassiicola and Botrytis cinerea. Front. Microbiol. 2018, 9, 1596. [CrossRef]

74. Langmead, B.; Salzberg, S.L. Fast gapped-read alignment with Bowtie 2. Nat. Methods 2012, 9, 357. [CrossRef]

75. Li, B.; Dewey, C.N. RSEM: Accurate transcript quantification from RNA-Seq data with or without a reference genome. $B M C$ Bioinform. 2011, 12, 323. [CrossRef] [PubMed]

76. Wang, L.; Feng, Z.; Wang, X.; Wang, X.; Zhang, X. DEGseq: An R package for identifying differentially expressed genes from RNA-seq data. Bioinformatics 2010, 26, 136-138. [CrossRef]

77. Garcion, C.; Metraux, J. FiRe and microarrays: A fast answer to burning questions. Trends Plant Sci. 2006, 11, 320-322. [CrossRef] [PubMed]

78. Czechowski, T.; Stitt, M.; Altmann, T.; Udvardi, M.K.; Scheible, W.R. Genome-wide identification and testing of superior reference genes for transcript normalization in Arabidopsis. Plant Physiol. 2005, 139, 5-17. [CrossRef] [PubMed]

79. Schmittgen, T.D.; Livak, K.J. Analyzing real-time PCR data by the comparative CT method. Nat. Protoc. 2008, 3, 1101-1108. [CrossRef] [PubMed]

80. Dubiella, U.; Seybold, H.; Durian, G.; Komander, E.; Lassig, R.; Witte, C.-P.; Schulze, W.X.; Romeis, T. Calcium-dependent protein kinase/NADPH oxidase activation circuit is required for rapid defense signal propagation. Proc. Natl. Acad. Sci. USA 2013, 110, 8744-8749. [CrossRef]

81. Liu, W.; Karemera, N.J.U.; Wu, T.; Yang, Y.; Zhang, X.; Xu, X.; Wang, Y.; Han, Z. The ethylene response factor AtERF4 negatively regulates the iron deficiency response in Arabidopsis thaliana. PLoS ONE 2017, 12, e0186580. [CrossRef] 